\title{
Conversion of marginal land into switchgrass conditionally accrues soil carbon and reduces methane consumption
}

\author{
Colin T. Bates, ${ }^{1,2}$ Arthur Escalas, ${ }^{3}$ Jialiang Kuang ${ }^{1}$, Lauren Hale, ${ }^{4}$ Yuan Wang, ${ }^{5}$ Don Herman, ${ }^{6,9}$ \\ Erin E. Nuccio, ${ }^{6}$ Xiaoling Wang, ${ }^{7}$ Ying Fu, ${ }^{1,2}$ Renmao Tian, ${ }^{1,2}$ Gangsheng Wang, ${ }^{1,2}$ Daliang \\ Ning, ${ }^{1,2}$ Yunfeng Yang, ${ }^{8}$ Liyou Wu, ${ }^{1,2}$ Jennifer Pett-Ridge, ${ }^{6}$ Malay Saha, ${ }^{5}$ Kelly Craven, ${ }^{5}$ Mary \\ Firestone, ${ }^{10}$ and Jizhong Zhou ${ }^{1,2,8,10}$ \\ 1 The Institute for Environmental Genomics, University of Oklahoma, Norman, OK, USA \\ 2 Department of Microbiology and Plant Biology, and School of Civil Engineering \\ and Environmental Sciences, University of Oklahoma, Norman, OK, USA \\ 3 MARBEC, University of Montpellier, Montpellier, France \\ 4 USDA, Agricultural Research Service, San Joaquin Valley Agricultural Sciences Center, \\ 9611 South Riverbend Avenue, Parlier, CA 93648-9757, USA \\ $5 \quad$ Noble Research Institute, Ardmore, OK \\ $6 \quad$ Physical and Life Sciences Directorate, Lawrence Livermore National Laboratory, \\ Livermore, CA 94551, USA \\ 7 The Key Laboratory of Aquatic Biodiversity and Conservation of the Chinese Academy \\ of Sciences; Institute of Hydrobiology, Chinese Academy of Sciences, Wuhan 430072, \\ China \\ 8 State Key Joint Laboratory of Environment Simulation and Pollution Control, School of \\ Environment, Tsinghua University, Beijing 100084, China \\ 9 Department of Environmental Science, Policy and Management, University of California, \\ Berkeley, CA 94720, USA \\ 10 Earth and Environmental Sciences, Lawrence Berkeley National Laboratory, Berkeley, \\ CA 94270, USA
}

\section{Abstract}

Switchgrass (Panicum virgatum L.) is a perennial $\mathrm{C}_{4}$ grass native to tallgrass prairies of the Central US, and a promising bioenergy feedstock. Switchgrass can be cultivated on soils with low nutrient contents and its rooting depth, of up to $2 \mathrm{~m}$, has brought attention to the crop as a potential mechanism to sequester and build soil carbon (C). Switchgrass, therefore, offers multifaceted benefits on degraded soils by enhancing soil organic matter content. However, to evaluate the sustainability of switchgrass-based biofuel production, it is crucial to understand the impacts of land conversion and switchgrass establishment on biotic/abiotic characteristics of 
various soils. In this study, we characterized the ecosystem-scale consequences of switchgrass growing at two highly-eroded, 'Dust Bowl' remnant field sites from Oklahoma US, with siltloam (SL) or clay-loam (CL) soil textures having low nitrogen $(\mathrm{N})$, phosphorus $(\mathrm{P})$, and $\mathrm{C}$ contents. Paired plots at each site, including fallow control and switchgrass-cultivated, were assessed. Our results indicated that switchgrass significantly increased soil C at the SL site and reduced microbial diversity at the CL site. The CL site exhibited significantly higher $\mathrm{CO}_{2}$ flux and higher respiration from switchgrass plots. Strikingly, switchgrass significantly reduced the

$42 \mathrm{CH}_{4}$ consumption by an estimated $39 \%$ for the SL site and $47 \%$ for the CL site. Structural 43 equation modeling identified soil temperature, $\mathrm{P}$ content, and soil moisture levels as the most

44 influential factors regulating both $\mathrm{CO}_{2}$ and $\mathrm{CH}_{4}$ fluxes. $\mathrm{CO}_{2}$ flux was also influenced by 45 microbial biomass while $\mathrm{CH}_{4}$ flux was influenced by microbial diversity. Together, our results

46 suggest that site selection by soil type is a crucial factor in improving soil $\mathrm{C}$ stocks and 47 mitigating greenhouse gas (GHG) fluxes, especially considering our finding that switchgrass 48 reduced methane consumption, implying that carbon balance considerations should be accounted 49 for to fully evaluate the sustainability of switchgrass cultivation.

Key words: Greenhouse Gases, Carbon Dioxide, Methane, Nitrous Oxide, Switchgrass, Soil Organic Matter, Carbon Sequestration, Biofuel 
57 'marginal' lands of low soil nutrient quality across Oklahoma and the Southwestern US (Texas,

58 Kansas, Colorado, and New Mexico). Since then, many of these sites have remained a 'poor' fit

59 for agricultural development. It has been suggested that the implementation of deep-rooted

60 perennial grasses may aid in soil restoration at these sites, offering economic benefits to farmers

61 in the form of cellulosic feedstock for bioenergy production (Gelfand et al., 2013).

62 Switchgrass (Panicum virgatum L.), a tall perennial deep-rooted grass native to the Central

63 North American Plains, is an auspicious bioenergy crop suitable for future large-scale cultivation

64 in the US (McLaughlin and Kszos, 2005). This enthusiasm for switchgrass stems from its

65 excellent ability to exhibit high biomass even on low-quality soils unfit for traditional

66 agricultural practices, with little to no additional inputs (Tilman et al., 2006). Long-term

67 cultivation experiments have suggested that switchgrass can improve soil productivity through

68 the net input of soil C (Gelfand et al., 2013, Ma et al., 2000). Therefore, large-scale switchgrass

69 cultivation may offset GHG emissions and serve as a means for improved soil fertility through C

70 sequestration at nutrient-poor sites (Anderson-Teixeria et al., 2009). Switchgrass is also known

71 to be highly drought tolerant (Barney et al., 2009) and can prevent topsoil erosion -two major

72 problems in the Central and Southwestern USA including states of OK, TX, KS, CO, and NM. It

73 is estimated that 15 million hectares of arable land would need to be converted into biofuel crop

74 in order to meet the US Department of Energy's plan to replace 30\% of transportation fossil fuels

75 with biofuels by 2030 (Bouton, 2007; Bouton, 2008). An estimated 11\% of the contiguous US is

76 considered nutrient-poor or 'marginal' land (Milbrandt et al., 2014) and currently represent an

77 under-utilized resource that may be well suited for switchgrass cultivation (Stoof et al., 2015).

78 Since perennial crop systems have high root biomass and exudates, they can improve soil C

79 stability and aggregate formation (Tiemann and Grandy, 2015). Like other perennial crops, 
Switchgrass has been broadly associated with increases in soil $\mathrm{C}$ at many different sites in the

81 central and northern Great American Plains (Liebig et at., 2008; Zan et al., 2001; Frank et al.,

82 2004; Dabney et al., 2004). However, this potential C accrual may be offset by higher soil

83 respiration arising from stimulated microbial $\mathrm{C}$ mineralization or increased root respiration.

Because soil microorganisms are critical drivers of soil nutrient cycling, understanding plant-microbe interactions during switchgrass cultivation could inform land management strategies toward the promoting of soil nutrient acquisition and recycling, along with reducing

87 GHG emissions. By examining microbial ecology of switchgrass influenced systems, researchers have revealed mechanistic understanding of the ways it enhances ecosystem services such as $\mathrm{C}$ sequestration, soil fertility, and GHG emissions (McLaughlin and Kszos, 2005; Ker et al., 2014; increase soil-surface carbon dioxide $\left(\mathrm{CO}_{2}\right)$ emissions despite increases in above (Mulkey et al., 2006; Lee at al., 2007) and below ground biomass (Sher et al., 2020). However, the relative impact of methane $\left(\mathrm{CH}_{4}\right)$ emissions during land conversions are not yet fully understood (Monti et al., 2012; Robertson and Grace, 2004; Fritsche et al., 2010). Additionally, the ecological consequences of land conversion, its impact on soil microbial ecology and functionality, as well

97 as the overall sustainability of switchgrass cultivation as a biofuel crop remain to be demonstrated. Further, only a few studies have evaluated switchgrass cultivation at sites with

99 low soil $\mathrm{N}, \mathrm{C}$, or $\mathrm{P}$ contents or in marginal lands that have experienced high rates of topsoil erosion (Gelfand et al., 2013; Ashiq et al., 2017). Particularly, we currently have a very limited understanding of how the transition from mixed annual grassland communities to switchgrass 
103 microbial biodiversity, and (iii) the overall prairie ecosystem functionality, specifically GHG 104 fluxes.

In this study, we monitored the ecosystem-level effects of switchgrass establishment over two consecutive growing seasons $(\mathrm{n}=17$ months) in two nutrient-poor (relatively low $\mathrm{N}, \mathrm{P}$, and C contents) field sites in Southern Oklahoma (designated SL for the silt-loam soil texture and CL

108 for the clay-loam soil texture). We compared switchgrass and natural fallow plots in terms of soil chemistry $(\mathrm{C}, \mathrm{N}$, and $\mathrm{P})$, soil $\mathrm{GHG}$ fluxes $\left(\mathrm{CO}_{2}, \mathrm{CH}_{4}\right.$, and $\left.\mathrm{N}_{2} \mathrm{O}\right)$, and microbial community composition. We tested the hypotheses that annual mixed grassland conversion to switchgrass (i) increases topsoil $\mathrm{C}$ levels over time; (ii) switchgrass increases $\mathrm{CO}_{2}$ respiration while maintaining similar $\mathrm{CH}_{4}$ emission and $\mathrm{N}_{2} \mathrm{O}$ flux relative to annual mixed grassland communities (fallows); and (iii) switchgrass modifies the microbial community during establishment and decreases species richness over time. We expect shifts in microbial community composition to correlate with observed GHG fluxes. Our results indicated that switchgrass had a site-specific, with increased $\mathrm{CO}_{2}$ respiration and decreases in microbial species richness observed only at the CL site, while soil C accumulation was observed only for the SL site. Switchgrass significantly reduced the methane consumption rates regardless of soil type.

\section{Methods}

\section{Field site, soil sampling, and root biomass estimation}

Samples were taken from two sites in southern Oklahoma, a silt-loam site (SL) near the Texas border $\left(34.18691^{\circ} \mathrm{N},-97.08487^{\circ} \mathrm{W}\right)$ and a clay-loam site (CL) in Ardmore $\left(34.172100^{\circ} \mathrm{N}\right.$, $\left.-97.07953^{\circ} \mathrm{W}\right)$. Prior to our experiment, each field site had experienced annual crop rotation and periods of being left fallow. At each site, a switchgrass field plot $(27$ x $22 \mathrm{~m})$ containing 500 
125

126

127

128

129

130

131

132

133

134

135

136

137

138

139

140

141

142

143

144

145

146

genetically distinct individuals of the lowland Alamo variety with a $1 \mathrm{~m}$ spacing between plants and a corresponding fallow plot $(27 \times 22 \mathrm{~m})$ were established in the summer of 2016 (Fig. S1a,b). All plots were tilled before planting switchgrass. Fallow plots were allowed to undergo natural succession of grasses and weeds over the time course of the experiment. To allow GHG measurements, at each plot, 21 PVC collars (diameter $23.63 \mathrm{~cm} \mathrm{x} 12.8 \mathrm{~cm} \mathrm{x} 1 \mathrm{~cm}$ ) (Fig. S1c) were embedded $8 \mathrm{~cm}$ into the soil and placed in a cross design (Fig. S1a,b) with five collars extending in each cardinal direction from a central origin collar at the center of each plot. After trace gas measurement from each collar, two soil cores $(15-20 \mathrm{~cm}$ in depth) were taken from within a $20 \mathrm{~cm}$ radius of each collar (Fig. S1d), thoroughly mixed, and separated into two bags, one for geochemical analyses and one for DNA extraction. Sampling flags were placed to prevent re-sampling the same location twice and each core was filled by topsoil taken from outside the plot. All soil samples were immediately stored on ice, transported back to the lab and kept at either $5 \square$ for geochemical analyses or $-80 \square$ for DNA extraction. In May 2017, total belowground root biomass was estimated using the Fraiser et al., 2016 method. Briefly, four 0-1 m cores were taken between six target plants and an adjacent plant (Fig. S2b). Soil cores were then divided into 5 depths for every $20 \mathrm{~cm}$ of soil. For each depth, roots were extracted from cores through sieving and soaking the soil in water. Roots from each layer of soil were collected, dried and massed from each layer. Switchgrass root biomass was estimated as described elsewhere (Frasier et al., 2016). For fallow plots, four randomly assigned $1 \mathrm{~m}^{2}$ subplots within each of the quadrants were selected to take four $0-1 \mathrm{~m}$ soil cores to represent root biomass across the plot (Fig. S2c). No roots were detected from fallow soil cores below $60 \mathrm{~cm}$ depth.

\section{Soil geochemistry, pH, and moisture}


Soil $\mathrm{pH}$, moisture, total available $\mathrm{C}, \mathrm{N}, \mathrm{P}$, nitrate $\left(\mathrm{NO}_{3}\right)$, and ammonium $\left(\mathrm{NH}_{4}\right)$ were measured following as described elsewhere (Hendershot et al., 2007). Briefly, $10 \mathrm{~g}$ of soil was placed into a $50 \mathrm{ml}$ tube with distilled $\mathrm{H}_{2} \mathrm{O}$ added to the $50 \mathrm{ml}$ fill line. Tubes were gently shaken

150 for 30 minutes and given an hour to settle before $\mathrm{pH}$ measurement using a $\mathrm{pH}$ probe (Acccumet excel XL15 pH meter, Fisher Scientific, Hampton NH, USA). Soil moisture was determined by a

152 gravimetric drying protocol that dried $>5 \mathrm{~g}$ of soil for one week at $>60 \square$ before re-massing to establish the percent of water lost after drying. To determine other soil geochemical parameters,

154 soil samples were dried in an oven at $60 \square$ for a week followed by sieving to remove unwanted 155 material with a $4 \mathrm{~mm}$ sieve. Soil samples were then shipped seasonally to the Oklahoma State University (OSU) soil testing lab where Mehlich III extractions (to quantify the available P in the soil), KCL extractions (to determine $\mathrm{NH}_{4}$ and $\mathrm{NO}_{3}$ concentrations) were performed and total soil C/N amounts were measured via dry combustion (LECO corporation, St. Joseph MI, USA).

\section{Environmental parameters}

Daily environmental data for 21 different environmental variables (at 5 to 15 -minute

162 belonging to the Oklahoma MESONET network (http://mesonet.org/) that were the closest to our 163 field sites (1.43 km and $2.3 \mathrm{~km}$ from SL and CL, respectively). Variables used included air 164 temperature, bare soil temperature, covered soil temperature, atmospheric pressure, relative 165 humidity, and precipitation (Table S1 and Table S2).

\section{Trace gas fluxes}

The $\mathrm{CO}_{2}, \mathrm{CH}_{4}$, and $\mathrm{N}_{2} \mathrm{O}$ fluxes were measured monthly via cavity ring-down 
169

170

171

172

173

174

175

176

177

178

179

180

181

182

183

184

185

186

187

188

189

were taken continuously every 2 seconds from a total of 6 minutes per collar. This allowed us to obtain gas concentrations in parts per million. Raw data from each gas were separated and then manually inspected to remove the beginning and the end of the measurements, which are often influenced by the pushing/pulling of the gas chamber. Then three models (linear, quadratic, and exponential) were fitted for each sample and gas species to characterize the variation of gas concentrations across time and the 'best model' was selected based on AIC scores. Flux estimations for each of the gases were then calculated using the following equation (Christiansen et al., 2015):

$$
F=\frac{d C}{d t} \cdot \frac{P V}{A \cdot R(273.15+T)} \times 3600
$$

Where $\frac{d c}{d t}$ is the slope of the best fitted model at $\mathrm{t}=0, \mathrm{~V}$ is the chamber volume $(\mathrm{L}), \mathrm{A}$ is the chamber area $\left(\mathrm{m}^{2}\right), \mathrm{R}$ is the gas constant in $\mathrm{L}_{\text {atm }} \mathrm{K}^{-1} \mathrm{~mol}^{-1}$, $\mathrm{T}$ is the temperature in Celsius, when the chamber pressure is assumed to be equal to $1 \mathrm{~atm}$. The 3600 factor is included to convert the flux to hourly values. For $\mathrm{CO}_{2}$ flux, $\mathrm{F}$ was then divided by 1000 to obtain the correct units of millimoles per $\mathrm{m}^{2}$ per hour.

\section{Soil DNA extractions, microbial community sequencing and analysis}

A freeze grinding method (Zhou et al., 1996) was combined with the Powersoil DNA extraction kit (Qiagen, Venlo, Netherlands) to extract DNA from a total of 1,428 soil samples, which typically yielded soil DNA of both high quantity and quality. For microbial community profiling a two-step PCR method (Wu et al., 2015) was used for amplification of the V4 region of the bacterial 16S rRNA gene using the 515F, 5'-GTGCCAGCMGCCGCGGTAA-3' and 806R, 5'-GGACTACHVGGGTWTCTAAT-3' primers. Sequencing of the 16S rRNA gene 
amplicons was conducted on the Illumina Mi-Seq DNA sequencing platform (Illumina Inc., San Diego, CA, U.S.A.). Amplicon sequence data was analyzed using an internal pipeline known as the Amplicon Sequencing Analysis Pipeline (Zhang et al., 2014) (ASAP, version 1.4). MiSeq sequences were quality checked with FastQC (version 0.11.5), pair-end sequences were merged based on their 3 ' overlap using PEAR (version 0.9 .10 ) with a quality score cutoff set to 20 , and assembly length between 200-400 with the minimum overlap length set to $50 \mathrm{bp}$. The program split_libraries_fastq.py from the QIIME package (Kuczynski et al., 2012) (version 1.9.1) was used to assign reads to each sample (demultiplexing) based on the barcodes for each individual sample with a maximum allowed barcode error of 0 and the trimming quality score set to 20 . Primer sequences were then trimmed and removed. Sequences from multiple split libraries were merged together. Dereplication was performed by USEARCH (Edgar, 2010) (version 9.2.64) using the command fastx_uniques (utilizing the size-out option for sequence abundance output). Operational Taxonomic Units (OTUs) were clustered using UPARSE, with the OTU identity threshold set to 0.97 and the singletons/chimeric sequences removed (Edgar, 2013). The OTU table was generated by the command -usearch_global in USEARCH. Each representative sequence for each OTU was classified with the RDP Classifier (Wang et al., 2007) (16S: training set 16 , June 2016) with the confidence cutoff set to 0.8 . OTUs in the $16 \mathrm{~S}$ sequence reads assigned to Chloroplast at the Order level were removed. Representative sequences for each OTU were used to construct a phylogenetic tree. Sequences were then aligned using MAFFT (Katoh, 2002) (version 3.8.31) and alignments were filtered using Gblocks (Castresana, 2000) (version 0.91b) with the options $-\mathrm{t}=\mathrm{d},-\mathrm{b} 4=3$ and $-\mathrm{b} 5=\mathrm{h}$. FastTree (Price et al., 2009) was used for constructing the phylogenetic tree using the filtered alignments. The phylogenetic tree and OTU 
212 tables were used to calculate alpha diversity (phylogenetic based indexes) and beta diversity

213 (UniFrac distance) using programs packaged in QIIME (Caporaso et al., 2010) and R.

\section{Statistical analyses}

All analyses were conducted using R statistical software (3.4.4, R Core Team, 2014) and

216 figures were produced using the package ggplot2 (Wickham, 2009). Data normality was tested

217 using the Shapiro test. We tested for differences between plots in GHG flux and microbial alpha

218 diversity by using linear mixed models to correct for repeated measurements (i.e. collars within

219 plots) and to analyze the data over time ( $\mathrm{R}$ package lme4, Bates et al., 2015). Pairwise comparisons for soil respiration between treatments were conducted using Wilcoxon Rank Sum

221 test and effect sizes were calculated using Mann-Whitney U Test. Differences in soil

222 biogeochemical properties between treatment were tested using Kruskal-Wallis test and effect

223 size was calculated using epsilon squared. Soil geochemical dissimilarity was calculated from

224 scaled data using Euclidean distances (vegan R package). Then mean dissimilarity across collars

225 was used to construct linear mixed models to view changes in dissimilarity over time.

226 Differences in microbial community structure across plot, site and time were tested using

227 PERMANOVA test based on Bray Curtis and weighted-UniFrac dissimilarity for taxonomic and

228 phylogenetic diversity, respectively. Differences in relative abundance between groups and time

229 points was calculated by multiple Student T-Tests and p-values were adjusted by conservative

230 Bonferroni correction to compensate for increased Type 1 errors over multiple time points.

Structural equation modeling (SEM) were used to explore the direct and indirect

232 relationships among environmental variables and $\mathrm{GHG}$ fluxes $\left(\mathrm{CO}_{2}\right.$ and $\left.\mathrm{CH}_{4}\right)$ at either site. We

233 first considered a full model that included all reasonable pathways, then eliminated 234 nonsignificant pathways until we obtained a final model with only significant pathways. We used 
235 a $\chi^{2}$ test and the root mean square error (RMSE) to evaluate the fit of our model. The SEM-

236 related analysis was performed using the lavaan R package (Rosseel, 2012).

\section{Results}

\section{Changes in soil geochemistry}

The conversion of grassland into switchgrass appeared to have a site-specific impact on soil geochemistry. A principal component analysis (PCA) of the soil geochemistry data revealed was higher at the CL site, as displayed by the dispersion of blue samples in Figure 1.

The total soil C at the SL site increased over the 17-month period in the switchgrass plot (Figure $2 \mathrm{a})\left(\mathrm{r}^{2}=0.12, \mathrm{p}<0.001\right)$ and was significantly higher than the fallow (Table $1, \mathrm{p}<$ contrast, the total soil C content remained constant in the CL switchgrass plot (Figure 2a).

251 over time $\left(\mathrm{r}^{2}=0.05, \mathrm{p}<0.01\right.$ ) (Figure $2 \mathrm{~b}$ ), coinciding with an increase in the soil $\mathrm{N}$ 252 heterogeneity in the plot $\left(r^{2}=0.12, p<0.0001\right)$ (Fig. S3b). A significant increase in the total soil

$253 \mathrm{~N}$ was notable in the CL fallow plot $\left(\mathrm{r}^{2}=0.12, \mathrm{p}<0.01\right)$ (Figure $\left.2 \mathrm{~b}\right)$. Nitrate concentration was 254 significantly reduced for the switchgrass treatment at the SL site (Table 1, p $<0.001$, small effect 255 size $=0.06$ ). All sites and plots showed a significant reduction in $\mathrm{NO}_{3}$ concentrations over time 
256

257

258

259

260

261

262

263

264

265

266

267

268

269

270

271

272 273 higher total root biomass. Figure 2c).

(Fig. S4) despite an increasing homogeneity (Fig. S3). No significant differences or trends were observed in $\mathrm{NH}_{4}$ concentrations during the length of our study at either site (Fig. S3e and S4b).

Total plant available $\mathrm{P}$ levels decreased over time in the SL site $\left(\mathrm{r}^{2}=0.05, \mathrm{p}<0.01\right)$ (Figure 2c) and the $\mathrm{P}$ content homogenized across the plot (Fig. S3c) despite the SL switchgrass treatment having significantly higher total plant available $\mathrm{P}$ content compared to the fallow (Table $1, \mathrm{p}<0.0001$, large effect size $=0.44$ ). In the CL site, plant available $\mathrm{P}$ also decreased in the switchgrass plot compared to the fallow (Table $1, \mathrm{p}<0.001$, medium effect size $=0.095$, and

\section{Differences in estimated root biomass}

Field-scale estimates of belowground root biomass (Fig. S2a) showed a large difference in the root biomass between each switchgrass plot and the corresponding fallow (17.8 and 64 times higher for SL and CL, respectively). Root biomass was estimated for each soil layer in kilograms per meter squared and compared to switchgrass estimates. Estimated total root biomass of the switchgrass plots was $16.9 \mathrm{~kg} / \mathrm{m}^{2}$ for the SL site and $14.1 \mathrm{~kg} / \mathrm{m}^{2}$ for the CL site, while the fallows were $0.95 \mathrm{~kg} / \mathrm{m}^{2}$ for $\mathrm{SL}$ and $0.22 \mathrm{~kg} / \mathrm{m}^{2}$ for CL. Generally, root biomass decreased along the soil depth profile for both sites. SL switchgrass site had increased root biomass estimates at lower depths $(60-100 \mathrm{~cm})$ than the CL site, which contributed to a slightly 
278

279

280

281

282

283

284

285

286

287

288

289

290

291

292

293

294

295

296

297

298

299

switchgrass planting (Wilcoxon $\mathrm{p}<0.001$, Figure 3a) while the fallow was significantly higher for only $24 \%$ of the total months measured. The average $\mathrm{CO}_{2}$ flux over the 17 -months did not differ in the SL site between switchgrass $\left(6.76 \pm 5.23\right.$ millimoles $\cdot \mathrm{m}^{2} \cdot$ hour $\left.^{-1}\right)$ and the fallow $(6.87$ \pm 5.87 millimoles $\cdot \mathrm{m}^{2} \cdot$ hour $\left.^{-1}\right)($ Figure $3 \mathrm{~d})$. At the CL site, there was a significant difference between treatments (Figure 3d) in the average $\mathrm{CO}_{2}$ flux over the 17 -month period $(\mathrm{p}<0.001)$ with the switchgrass plot at $9.98 \pm 6.04$ millimoles $\cdot \mathrm{m}^{2} \cdot$ hour $^{-1}$ and the fallow at $9.22 \pm 6.62$ millimoles $\cdot \mathrm{m}^{2} \cdot$ hour $^{-1}$, although the effect size was small $(0.13)$. When comparing the two sites, CL exhibited significantly higher total soil $\mathrm{CO}_{2}$ fluxes for both switchgrass and fallow plots than those measured at SL (Wilcoxon $\mathrm{p}<0.001$ ).

$\mathrm{CH}_{4}$ flux (Figure 3b, Table S3) differed significantly between switchgrass and fallow (Wilcoxon $\mathrm{p}<0.001$, small effect size $=0.15$ ), with a tendency toward higher $\mathrm{CH}_{4}$ emissions or lower $\mathrm{CH}_{4}$ consumption levels in the switchgrass plot observed for $41 \%$ of the months (Figure 3b) after switchgrass was planted (41\% and $52 \%$ for CL and SL, respectively). $\mathrm{CH}_{4}$ flux in the fallow was higher only at one time point $\left(14^{\text {th }}\right.$ month after switchgrass establishment). Overall, the 17-month average $\mathrm{CH}_{4}$ consumption rate was $-0.44 \pm 1.07$ micromoles $\cdot \mathrm{m}^{2} \cdot$ hour $^{-1}$ for switchgrass treatments $\left(-0.46 \pm 1.08\right.$ and $-0.41 \pm 1.06$ micromoles $\cdot \mathrm{m}^{2} \cdot \mathrm{hour}^{-1}$ for $\mathrm{CL}$ and $\mathrm{SL}$, respectively) while it reached $-0.77 \pm 1.15$ in the fallow $(-0.76 \pm 1.78$ and $-0.77 \pm 0.53$ and micromoles $\cdot \mathrm{m}^{2} \cdot$ hour $^{-1}$ for CL and SL, respectively) (Figure 3e, Table S3). Together, a significant $(\mathrm{p}<0.05$, a small effect size $=0.14)$ switchgrass treatment effect on reducing $\mathrm{CH}_{4}$ consumption rates was observed at both sites. No significant differences were found for $\mathrm{N}_{2} \mathrm{O}$ flux between the switchgrass $\left(-0.26 \pm 2.55\right.$ micromoles $\cdot \mathrm{m}^{2} \cdot$ hour $^{-1}$ at CL and $-2.88 \pm 2.09$ micromoles $\cdot \mathrm{m}^{2} \cdot$ hour $^{-1}$ at SL) and fallow plots $\left(-1.65 \pm 2.5\right.$ micromoles per $\mathrm{m}^{2}$ per hour at CL and $-5.01 \pm 2.16$ micromoles 
300 per $\mathrm{m}^{2}$ per hour at SL) at either site (Figure 3c, Table S3) over the 17-months of observations 301 (Figure 3f).

\section{Microbial community dynamics}

Microbial alpha diversity, calculated as the OTU richness, responded in a site-specific manner to switchgrass cultivation. In the SL site, OTU richness was significantly higher in the switchgrass plot (Table S3, p $<0.0001$, Medium effect size $=0.38$ ). OTU richness did not change over time in the SL switchgrass plot (Figure 4a) but increased in the fallow plot $(\mathrm{p}<$ 0.001), despite a decrease in phylogenetic diversity (PD) $(\mathrm{p}<0.05$, Figure 4a,b). At the CL site, species richness decreased significantly over time in both switchgrass $(\mathrm{p}<0.01)$ and fallow plots $(\mathrm{p}<0.001)$. For PD, this decay was observed only in the switchgrass plot $(\mathrm{p}<0.01)$. Chaol and Shannon index showed similar trends per site over time (Fig. S5). phyla exhibited changes in relative abundance. Firmicutes phyla relative abundance $(0.6-0.14$

317 communities from the switchgrass plots appeared less variable than their corresponding fallows.

318 In the CL site, the strongest differences in dominant phyla relative abundance between plots

319 (switchgrass vs fallow) were observed at eight and fourteen months after switchgrass planting 320 (Feb. 2017 and Aug. 2017, Table S5). After eight months, seven phyla (Actinobacteria,

321 Bacteroidetes, Chloroflexi, Deinococcus-Thermus, Firmicutes, Plactomycetes, and 322 Verrucomicrobia) exhibited different abundance between treatment, while only four phyla 
323 (Actinobacteria, Chloroflexi, Cyanobacteria, and Deinococcus-Thermus) were different after

324 fourteen months. For the SL site, the largest shifts in community composition occurred in the last

325 two time points, i.e. fourteen and sixteen months after switchgrass establishment. After fourteen

326 months, three phyla were significantly different between treatment (Acidobacteria, Bacteroidetes

327 and Deinococcus-Thermus) and after sixteen months four groups were significantly different

328 (Acidobacteria, Bacteroidetes, Cyanobacteria, and Verrucomicrobia).

Canonical correspondence analysis (CCA) was used to link environmental variables to the microbial community (Figure 6). A clear separation between microbial communities from the two sites was observed. Microbial communities from the SL site were correlated with plant available $\mathrm{P}$ and soil $\mathrm{pH}$, while $\mathrm{CL}$ communities were associated with total soil $\mathrm{N}, \mathrm{NH}_{4}$, and $\mathrm{NO}_{3}$. In addition, fallow communities from CL were dispersed, while switchgrass communities at this site were clustered by $\mathrm{N}$ source or along a soil moisture profile.

\section{Structural equation model}

Structural equation modeling (SEM) was used for an in-depth analysis of the direct and

337 indirect effects of the environmental drivers on $\mathrm{CO}_{2}$ and $\mathrm{CH}_{4}$ flux for both sites. Correlations

338 between all variables are shown in the correlogram Figure S6. For $\mathrm{CO}_{2}$ fluxes (Figure 7a) the 339 model confirmed the importance of the site effect on soil geochemistry and microbial 340 communities, with the strongest direct effects (based on standardized coefficient) being directed 341 from the site towards total $\mathrm{C}(\beta=-0.95, \mathrm{p}<0.001)$, total $\mathrm{N}(\beta=-0.94, \mathrm{p}<0.001)$, $\mathrm{P}$ levels $(\beta=$ $3420.88, \mathrm{p}<0.001)$, and microbial alpha diversity $(\beta=0.52, \mathrm{p}<0.001)$. Plant available $\mathrm{P}$ tended to 343 influence the levels of $\mathrm{C}$ and $\mathrm{N}$ in the system, and these three components of soil have significant 344 effects on $\mathrm{CO}_{2}$ fluxes. Other important variables influencing $\mathrm{CO}_{2}$ fluxes included soil 345 temperature $(\beta=0.69, \mathrm{p}<0.001)$, moisture $(\beta=0.27, \mathrm{p}<0.001)$ and microbial biomass $(\beta=-$ 
$0.18, \mathrm{p}<0.001)$. This later variable appeared mostly dependent on $\mathrm{N}$ content $(\beta=0.56, \mathrm{p}<$ 0.001).

In the $\mathrm{CH}_{4}$ model (Figure $7 \mathrm{~b}$ ), which was focused on the switchgrass plots, the site effect appeared less pronounced and mostly directed toward $\mathrm{P}$ levels $(\beta=-0.29, \mathrm{p}<0.001)$ and microbial alpha diversity $(\beta=0.62, \mathrm{p}<0.001)$. Although soil temperature did not have a very

351

352

353

354

strong influence on $\mathrm{CH}_{4}$ fluxes $(\beta=-0.19, \mathrm{p}<0.001)$, it was still important in this model through

many direct effects on $\mathrm{P}(\beta=0.07, \mathrm{p}<0.001), \mathrm{NO}_{3}(\beta=0.23, \mathrm{p}<0.001)$, $\mathrm{pH}(\beta=-0.22, \mathrm{p}<$ $0.001)$, microbial diversity $(\beta=0.11, \mathrm{p}<0.001)$, and moisture $(\beta=-0.39, \mathrm{p}<0.001)$. Overall, we were able to show that $\mathrm{CH}_{4}$ fluxes depended on a combination of soil chemical properties ( $\mathrm{P}$ and $\mathrm{NO}_{3}$ ) along with physical (temperature and moisture) and biological (microbial diversity) characteristics.

quality and appears crucial for its use as a sustainable bioenergy feedstock. It was hypothesized that switchgrass would increase (i) topsoil $\mathrm{C}$ levels and (ii) increased $\mathrm{CO}_{2}$ respiration -with (iii) little effect on $\mathrm{CH}_{4}$ emissions and $\mathrm{N}_{2} \mathrm{O}$ flux, but also (iv) decreased the bulk soil microbial species richness relative to annual mixed grassland communities. While $\mathrm{C}$ accrual, $\mathrm{CO}_{2}$ respiration, and microbial richness reductions were site-dependent in our study, switchgrass significantly altered the soil $\mathrm{CH}_{4}$ sink capacity at both sites by reducing the overall $\mathrm{CH}_{4}$ consumption rates. Although the $\mathrm{CH}_{4}$ emission rates reported here were expectedly lower than those reported for natural systems with anaerobic, water-logged conditions like peatlands (Dise, 1993) and wetlands (Bridgham et al., 2013; Bartlett and Harriss, 1993), our findings challenged 
368

369

370

371

372

373

374

375

376

377

378

379

380

381

382

383

384

385

386

387

388

389

the notion that $\mathrm{CH}_{4}$ emissions has negligible effects on $\mathrm{GHG}$ budgets during marginal land transitions to switchgrass row-cropping (Monti et al., 2012). However, comprehensive GHG budgets along with spatial-explicit modeling of soil and plant $\mathrm{C}$ stocks should be considered to fully evaluate the net effect of land type conversion at these prairie sites.

\section{Soil type dictates the effects that switchgrass has on geochemistry}

Our study revealed significant site-level differences to switchgrass establishment on soil C accrual, total soil $\mathrm{N}$ levels and depletion of soil P content. The CL site with higher relative nutrient content showed little change over time (17 months) for any of the soil geochemical parameters. Ma et al., 2000 reported changes in soil geochemistry by switchgrass cultivation in clay-loam soils were only detected after longer periods of time (over a decade). Therefore, prolonged sampling at our CL site will improve assessments of switchgrass-induced soil C changes. Nitrate contents (Figure S4a) significantly declined with time, which may suggest assimilation by the switchgrass or an increased activity of denitrifying bacteria. It is also notable that the crop was grown under natural conditions without applying any chemical fertilizers.

The SL site showed significant increases in soil C content for the top-soil layer (27\% higher total $\mathrm{C}$ after two growing seasons) over the course of switchgrass establishment. This is consistent with estimates of switchgrass systems repaying their $\mathrm{C}$ debt in a relatively short amount of time (Abrah et al., 2019). However, switchgrass led to significant depletions in soil $\mathrm{N}$ and P contents at the SL site over time, though these values were higher than the fallow from the beginning of our experiment. One explanation for this observation is the increased below ground root biomass estimates being larger for the SL site at lower depths. Greater investment of belowground root biomass may reflect the higher plant available $\mathrm{P}$ conditions at this site, 
390 allowing switchgrass to extend deeper into the subsurface soil for water or micronutrient 391 availability.

Seasonal sampling of $\mathrm{NH}_{4}-\mathrm{N}$ sources was not sufficient in explaining large seasonal variations observed over the time course of our experiment. For example, a spike in soil $\mathrm{NH}_{4}$

394 levels (Figure S4b) was detected during October of 2016 and June of 2017, which could be the 395 signature of episodic $\mathrm{N}$ fixation events occurring in switchgrass during/before flowering as 396 reported previously (Roley et al., 2019). However, our resolution in sampling this geochemical 397 parameter is not sizeable enough to adequately explain these anomalies.

\section{Microbial community shifts under switchgrass establishment}

Microbial community diversity and composition at each site had differential responses to switchgrass establishment. Broadly, alpha diversity measures in CL decreased over time and revealed a higher amount of clustering and similarity in the overall community structure compared with the fallow. Analogous to secondary plant successional dynamics, the microbial 403 community at the CL site may be more influenced by the change from short rooted annuals to the 404 monoculture of deep-rooted perennial switchgrass, causing a loss in microbial diversity (Cline 405 and Zak, 2015). For SL, switchgrass cultivation significantly increased the Shannon index over 406 time and caused the community composition to shift away from the fallow. This may be 407 indicative of the improvements of soil quality, which changed the functionality of the microbial 408 community due to the influence of switchgrass on increases in soil C levels (Leff et al., 2015).

Microbial community structure was altered by switchgrass establishment (Table S4) and through time at each of the sites relative to the fallow soil communities. These changes in

411 community structure may reflect different survival strategies that switchgrass may employ in the 
412 recruitment of specific taxa to its rhizosphere based of differences between the geochemistry of

413 the two sites. Investigations into rhizosphere microbiome succession during establishment may

414 provide insights into direct plant-microbe interactions that facilitate switchgrass establishment in

415 these nutrient-poor soils.

\section{Factors controlling soil GHG flux}

417 Contrary to our hypothesis, $\mathrm{CO}_{2}$ respiration was significantly enhanced by switchgrass 418 establishment only at the CL site. We expected higher root respiration and the potential for deep $419 \mathrm{C}$ mineralization to enhance soil respiration at both sites after switchgrass establishment 420 (Shahzad et al., 2018; Fontaine et al., 2007). The CL site had an overall higher total $\mathrm{CO}_{2}$ 421 emission rate during our field monitoring. This response may be mediated by the relatively 422 higher preexisting $\mathrm{C}$ nutrient conditions found at this clay-loam site (Kang et al., 2016) as root 423 biomass levels were estimated to be similar at each site. This illustrates a benefit in site selection 424 by soil type in minimizing $\mathrm{CO}_{2}$ released during land conversion.

425 Nitrous oxide fluxes did not show any significant effect between either site or plant cover 426 type. Thus, we did not see an effect of switchgrass or site on nitrous oxide fluxes. However, 427 nitrous oxide fluxes were marked by high variability, both seasonally and spatially within each 428 plot. Efforts were made to correlate rainfall events to reduce noise in the flux signal, but a 429 substantial limitation was our six-minute window of continuous measurements per sampling 430 event. A longer period of trace gas sampling may have resulted in a more stable signal with less 431 variability for nitrous oxide fluxes. 
434

435

436

437

438

439

440

441

442

443

444

445

446

447

448

449

450

451

452

453

454

455

measured at only a few time points, consistently lower $\mathrm{CH}_{4}$ consumption rates were observed throughout the monitoring period of our experiment. Total methane consumption rates for switchgrass plots were reduced by $47 \%$ and $39 \%$ compared to corresponding fallow sites for CL and SL, respectively. This could reflect considerable differences in the net $\mathrm{C}$ budget and fluxes for these switchgrass sites. In the future, GeoChip-based functional microarray (Shi et al., 2019) as well as, $\mathrm{RT}$-qPCR of $\mathrm{CH}_{4}$ monooxygenase and methyl-coenzyme $\mathrm{M}$ reductase genes may help provide us with specific linkages between microbial functionality potential and our reported $\mathrm{CH}_{4}$ emissions at key time points during our experimental monitoring.

\section{Conclusion}

Overall, soil C levels increased by $27 \%$ during the 17 months experiment in the site with the lowest nutrient content (silt loam, SL) while they remained consistent in the clay loam (CL) site. Switchgrass significantly affected total $\mathrm{CO}_{2}$ respiration at the CL site, but not at the SL site compared to the annual mixed grassland community fallows and showed a difference in the site level emissions. Grassland conversion to switchgrass reduced the annual $\mathrm{CH}_{4}$ consumption by 39 to $47 \%$, implying that methane fluxes should be accounted for in $\mathrm{C}$ budgets to reach a sustainable cultivation of switchgrass. Switchgrass establishment had a significant influence on the microbial community composition over time. Our SEM analysis indicated that soil temperature and moisture were strong environmental drivers of the soil the $\mathrm{CO}_{2}$ and $\mathrm{CH}_{4}$ flux at each site. Considerations on soil type and nutrient conditions should be made for the selection of future sites suitable for large-scale bioenergy cultivation of that meets objectives for terrestrial C sequestration and improved soil fertility. 


\section{Acknowledgements}

457 We would like to thank the Oklahoma Mesonet environmental monitoring network, and 458 particularly Bradley Ilston, for the use of their weather monitoring stations for this work. We 459 deeply appreciate all the help from the auxiliary staff and field hands from the Nobel Research 460 Institute, who aided in us in collecting data and maintaining the field sites for this project. A.

461 Escalas and C. Bates would like to give a special thanks to Randy Freeman, who helped a lot for 462 making sample collection and processing possible. We would also like to thank the following for 463 their contributions in field sampling and molecular work: Zhigang Wang, Yuguang Zhang, Ning $464 \mathrm{Hu}$, Yan He, Zhongfang Li, Qian Li, Jinyu Hou, Xiubin Ke, Juan Ling, Zheng Gao, and Daniel 465 Curtis. C. Bates would also like to thank Cheryl Bates for edits and Tanya Ball for support 466 during this project. This research is supported by the U.S. Department of Energy Office of 467 Science, Office of Biological and Environmental Research Genomic Science program under the 468 award number DE-SC0014079 to the UC Berkeley, Nobel Research Institute, University of 469 Oklahoma, the Lawrence Livermore National Laboratory, and the Lawrence Berkeley National 470 Laboratory. 


\section{References}

474

475

476

477

478

479

480

481

482

483

484

485

486

487

488

489

490

491

492

493

494

495

1. Abraha M, Gelfand I, Hamilton SK, Chen J, Robertson GP. Carbon debt of field-scale conservation reserve program grasslands converted to annual and perennial bioenergy crops. Environ Res Lett. 2019;

2. Anderson-Teixeria KJ, Davis SC, Masters MD, Delucia EH. Changes in soil organic carbon under biofuel crops. GCB Bioenergy. 2009;

3. Ashiq MW, Bazrgar AB, Fei H, Coleman B, Vessey K, Gordon A, et al. A nutrient-based sustainability assessment of purpose-grown poplar and switchgrass biomass production systems established on marginal lands in Canada. Can J Plant Sci. 2017;

4. Bahulikar RA, Torres-Jerez I, Worley E, Craven K, Udvardi MK. Diversity of nitrogenfixing bacteria associated with switchgrass in the native tallgrass prairie of Northern Oklahoma. Appl Environ Microbiol. 2014;

5. Barney JN, Mann JJ, Kyser GB, Blumwald E, Van Deynze A, DiTomaso JM. Tolerance of switchgrass to extreme soil moisture stress: Ecological implications. Plant Sci. 2009;

6. Bartlett KB, Harriss RC. Review and assessment of methane emissions from wetlands. Chemosphere. 1993;

7. Bates D, Mächler M, Bolker BM, Walker SC. Fitting linear mixed-effects models using lme4. J Stat Softw. 2015;

8. Baumhardt LR. Dust Bowl Era. In: Encyclopedia of Water Science. 2003.

9. Bouton JH. Molecular breeding of switchgrass for use as a biofuel crop. Current Opinion in Genetics and Development. 2007;

10. Bouton, J. in Genetic Improvement of Bioenergy Crops (ed W. Vermerris) 295-308 Springer Science and Business Media, 2008; 

wetlands: Biogeochemical, microbial, and modeling perspectives from local to global scales. Glob Chang Biol. 2013; QIIME allows analysis of high-throughput community sequencing data. Nature Methods. 2010;

13. Castresana J. Selection of conserved blocks from multiple alignments for their use in phylogenetic analysis. Mol Biol Evol. 2000;

14. Christiansen JR, Outhwaite J, Smukler SM. Comparison of CO2, CH4 and N2O soilatmosphere exchange measured in static chambers with cavity ring-down spectroscopy and gas chromatography. Agric For Meteorol. 2015; fractions in acidic soil. Commun Soil Sci Plant Anal. 2005;

16. Cline LC, Zak DR. Soil microbial communities are shaped by plant-driven changes in resource availability during secondary succession. Ecology. 2015; modified by establishing grass hedges. Trans Am Soc Agric Eng. 2004;

\section{$514 \quad$ Global Biogeochem Cycles. 1993;}

19. Edgar RC. Search and clustering orders of magnitude faster than BLAST. Bioinformatics. 2010 Nat Methods. 2013; 
21. Fontaine S, Barot S, Barré P, Bdioui N, Mary B, Rumpel C. Stability of organic carbon in deep soil layers controlled by fresh carbon supply. Nature. 2007;

22. Frank AB, Berdahl JD, Hanson JD, Liebig MA, Johnson HA. Biomass and carbon partitioning in switchgrass. Crop Sci. 2004; quantification in agroecosystems. MethodsX. 2016;

24. Fritsche UR, Sims REH, Monti A. Direct and indirect land-use competition issues for Biorefining. 2010; bioenergy production from marginal lands in the US Midwest. Nature. 2013;

26. Ghimire SR, Charlton ND, Craven KD. The mycorrhizal fungus, sebacina vermifera, enhances seed germination and biomass production in switchgrass (panicum virgatum l). Bioenergy Res. 2009; Production under Drought Conditions by the Ectomycorrhizal Fungus Sebacina vermifera. Appl Environ Microbiol. 2011; switchgrass (Panicum virgatum L.) biofuel cultivation in the Central Great Plains, USA. Biomass and Bioenergy. 2011;

29. Hendershot W, Lalande H, Duquette M. Soil Reaction and Exchangeable Acidity. In: Soil Sampling and Methods of Analysis, Second Edition. 2007; 
30. Jobbágy EG, Jackson RB. The distribution of soil nutrients with depth: Global patterns and the imprint of plants. Biogeochemistry. 2001;

31. Kang H, Fahey TJ, Bae K, Fisk M, Sherman RE, Yanai RD, et al. Response of forest soil respiration to nutrient addition depends on site fertility. Biogeochemistry. 2016;

32. Katoh K. MAFFT: a novel method for rapid multiple sequence alignment based on fast Fourier transform. Nucleic Acids Res. 2002;

33. Ker K, Seguin P, Driscoll BT, Fyles JW, Smith DL. Evidence for enhanced N availability during switchgrass establishment and seeding year production following inoculation with rhizosphere endophytes. Arch Agron Soil Sci. 2014;

34. Kim S, Lowman S, Hou G, Nowak J, Flinn B, Mei C. Growth promotion and colonization of switchgrass (Panicum virgatum) cv. alamo by bacterial endophyte burkholderia phytofirmans strain PsJN. Biotechnol Biofuels. 2012;

35. Kuczynski J, Stombaugh J, Walters WA, González A, Caporaso JG, Knight R. Using QIIME to analyze 16s rRNA gene sequences from microbial communities. Curr Protoc Microbiol. 2012;

36. Lee DK, Doolittle JJ, Owens VN. Soil carbon dioxide fluxes in established switchgrass land managed for biomass production. Soil Biol Biochem. 2007;

37. Leff JW, Jones SE, Prober SM, Barberán A, Borer ET, Firn JL, et al. Consistent responses of soil microbial communities to elevated nutrient inputs in grasslands across the globe. Proc Natl Acad Sci U S A. 2015;

38. Liang C, Jesus E da C, Duncan DS, Quensen JF, Jackson RD, Balser TC, et al. Switchgrass rhizospheres stimulate microbial biomass but deplete microbial necromass in agricultural soils of the upper Midwest, USA. Soil Biol Biochem. 2016; 

Grown for Bioenergy. BioEnergy Res. 2008; switchgrass. Biomass and Bioenergy. 2000; bioenergy feedstock in the United States. Biomass and Bioenergy. 2005; marginal lands in the United States. Renewable and Sustainable Energy Reviews. 2014; reducing GHG emissions. GCB Bioenergy. 2012. reserve program lands for biomass production in South Dakota. Crop Sci. 2006; profiles instead of a distance matrix. Mol Biol Evol. 2009;

46. Robertson GP, Grace PR. Greenhouse gas fluxes in tropical and temperate agriculture: The need for a full-cost accounting of global warming potentials. Environ Dev Sustain.

47. R Core Team. R Core Team (2014). R: A language and environment for statistical 2004; computing. R Found Stat Comput Vienna, Austria URL http//wwwR-project.org/. 2014; nitrogen fixation in switchgrass (Panicum virgatum L.). Soil Biol Biochem. 2019; 
50. Schubert SD, Suarez MJ, Pegion PJ, Koster RD, Bacmeister JT. On the Cause of the 1930s Dust Bowl. Science (80- ). 2004;

51. Shahzad T, Rashid MI, Maire V, Barot S, Perveen N, Alvarez G, et al. Root penetration in deep soil layers stimulates mineralization of millennia-old organic carbon. Soil Biol Biochem. 2018;

52. Sher Y, Baker NR, Herman D, Fossum C, Hale L, Zhang X, et al. Microbial extracellular polysaccharide production and aggregate stability controlled by switchgrass (Panicum virgatum) root biomass and soil water potential. Soil Biol Biochem. 2020;

53. Shi Z, Yin H, Van Nostrand JD, Voordeckers JW, Tu Q, Deng Y, et al. Functional Gene Array-Based Ultrasensitive and Quantitative Detection of Microbial Populations in Complex Communities. mSystems. 2019;

54. Stoof CR, Richards BK, Woodbury PB, Fabio ES, Brumbach AR, Cherney J, et al. Untapped Potential: Opportunities and Challenges for Sustainable Bioenergy Production from Marginal Lands in the Northeast USA. Bioenergy Research. 2015;

55. Tiemann LK, Grandy AS. Mechanisms of soil carbon accrual and storage in bioenergy cropping systems. GCB Bioenergy. 2015;

56. Tilman D, Hill J, Lehman C. Carbon-negative biofuels from low-input high-diversity grassland biomass. Science (80- ). 2006;

57. Wang Q, Garrity GM, Tiedje JM, Cole JR. Naïve Bayesian classifier for rapid assignment of rRNA sequences into the new bacterial taxonomy. Appl Environ Microbiol. 2007;

58. Wickham H. ggplot2: elegant graphics for data analysis. Springer New York. 2009; 
59. Worster D. Dust bowl: the Southern Plains in the 1930s ( Oklahoma and Kansas). Dust bowl South Plains 1930s (Oklahoma Kansas). 1982; sequencing on Illumina Miseq for robust environmental microbial community analysis. BMC Microbiol. 2015;

61. Zan CS, Fyles JW, Girouard P, Samson RA. Carbon sequestration in perennial bioenergy, annual corn and uncultivated systems in southern Quebec. Agric Ecosyst Environ. 2001;

62. Zhang J, Kobert K, Flouri T, Stamatakis A. PEAR: A fast and accurate Illumina PairedEnd reAd mergeR. Bioinformatics. 2014;

618 63. Zhou J, Bruns MA, Tiedje JM. DNA recovery from soils of diverse composition. Appl Environ Microbiol. 1996; after 17-months. Values are mean \pm SD values and significance was tested axis are displayed next to each axis. 

model describing the relationship is presented. $\mathrm{W}_{\mathrm{s}}$ : estimated model slope and associated error. p-values represent the significance of each model. Each time point is comprised of twenty-one replicates per plot.

\section{Figure 3. Greenhouse gas (GHG) fluxes during grassland conversion to switchgrass.} groups by Wilcox sign test with p-value $<0.01$. bar. 

structure with environmental variables. Samples are shown by plot and site type with significant environmental variables shown in black arrows.

\section{Figure 7. Structural equation modeling showing the relationships among}

657

658

659

660

661

662

663

664

665

666

667

668

669

670

671

672

673 environmental variables and GHG fluxes. a: Model for total carbon dioxide flux generated from the seasonal data $\left(\chi^{2}=25.806\right.$, d.f. $\left.=18, P=0.104, n=588\right)$. b: Model for methane flux generated from seasonal data of switchgrass plots only $\left(\chi^{2}=10.116\right.$, d.f. $=9, P=0.341, n=294)$. Red and blue arrows represent significant $(\mathrm{p}<0.05)$ positive and negative pathways, respectively. Numbers near the pathway arrows indicate the standard path coefficients $(\beta)$. Width of the arrows are proportional to the strength of the relationship. Gray arrows represent residual correlations accounted for in the model. Plant Cover $=$ Switchgrass $($ positive) or mixed annual grassland plant cover (negative) at the plot; Site $=\mathrm{SL}$ (positive) or $\mathrm{CL}$ (negative) soil site $\mathrm{CO}_{2}=$ total soil carbon dioxide flux; Soil Temp = soil temperature at a depth of $10 \mathrm{~cm}$ for bare soil in degrees Celsius; Soil Moisture $=$ gravimetric per cent soil moisture; $\mathrm{P}=$ plant available phosphorus content; Microbial Alpha Diversity = number of observed bacterial species per sample; $\mathrm{NO}_{3}=$ nitrate concentrations; $\mathrm{CH}_{4}=$ methane flux; and $\mathrm{pH}=$ soil $\mathrm{pH}$. 
bioRxiv preprint doi: https://doi.org/10.1101/2020.03.18.997304; this version posted March 20, 2020. The copyright holder for this preprint (which was not certified by peer review) is the author/funder. All rights reserved. No reuse allowed without permission.

674 


\section{Table}

Table 1: Differences in physico-chemical soil properties for each site and treatment after 17-months. Values are mean \pm SD values and significance was tested by Kruskal-Wallis rank sum test.

\begin{tabular}{|c|c|c|c|c|c|c|c|c|c|c|}
\hline \multirow{2}{*}{ Variable } & \multirow{2}{*}{$\begin{array}{c}\text { Silt Loam } \\
\text { Fallow } \\
\text { Mean } \pm \text { SD }\end{array}$} & \multirow{2}{*}{$\begin{array}{c}\text { Silt Loam } \\
\text { Switchgrass } \\
\text { Mean } \pm \text { SD }\end{array}$} & \multicolumn{3}{|c|}{ Kruskal-Wallis Tests } & \multirow{2}{*}{$\begin{array}{l}\text { Clay Loam } \\
\text { Fallow } \\
\text { Mean } \pm \text { SD }\end{array}$} & \multirow{2}{*}{$\begin{array}{c}\text { Clay Loam } \\
\text { Switchgrass } \\
\text { Mean } \pm \text { SD }\end{array}$} & \multicolumn{3}{|c|}{ Kruskal-Wallis Tests } \\
\hline & & & $\begin{array}{c}\text { Chi- } \\
\text { squared }\end{array}$ & $\mathbf{p}$ & Effect Size & & & $\begin{array}{c}\text { Chi- } \\
\text { squared }\end{array}$ & $\mathbf{p}$ & Effect Size \\
\hline $\mathrm{pH}$ & $6.5 \pm 0.67$ & $6.7 \pm 0.95$ & 1.32 & 0.25 & - & $5.73 \pm 0.44$ & $5.85 \pm 0.57$ & 2.17 & 0.14 & - \\
\hline $\begin{array}{l}\text { Soil Moisture } \\
(\%)\end{array}$ & $7.1 \pm 4.1$ & $8.7 \pm 6$ & 3.27 & 0.07 & - & $10.4 \pm 6.8$ & $9.82 \pm 5.5$ & 0.75 & 0.39 & - \\
\hline Total soil C (\%) & $0.47 \pm 0.09$ & $0.61 \pm 0.12$ & 118 & $<0.0001 * * *$ & 0.40 Large & $1.3 \pm 0.42$ & $1.3 \pm 0.36$ & 0.86 & 0.40 & - \\
\hline Total soil N (\%) & $0.06 \pm 0.01$ & $0.07 \pm 0.01$ & 55.4 & $<0.0001 * * *$ & 0.19 Medium & $0.11 \pm 0.02$ & $0.11 \pm 0.02$ & 0.27 & 0.6 & - \\
\hline $\begin{array}{c}\text { Phosphorus } \\
\text { (ppm) }\end{array}$ & $55.6 \pm 13$ & $73.7 \pm 9.7$ & 128 & $<0.0001 * * *$ & 0.44 Large & $22.6 \pm 9.7$ & $17.5 \pm 6.5$ & 27.7 & $<0.001 * *$ & 0.095 Medium \\
\hline Nitrate (ppm) & $3.5 \pm 3.7$ & $2.2 \pm 3$ & 16.8 & $<0.001 * *$ & 0.06 Small & $8.3 \pm 9.8$ & $8.9 \pm 15$ & 2.37 & 0.12 & - \\
\hline (ppm) & $13.6 \pm 11$ & $14.5 \pm 10$ & 1.73 & 0.19 & - & $18.5 \pm 11$ & $17.9 \pm 11.5$ & 0.61 & 0.44 & - \\
\hline
\end{tabular}

678

*Effect size shown by epsilon squared with small $(0.01-<0.08)$, medium $(0.08-<0.26)$, and large $(\geq 0.26)$ ranges.

679 


\section{Figures}

683

684

685

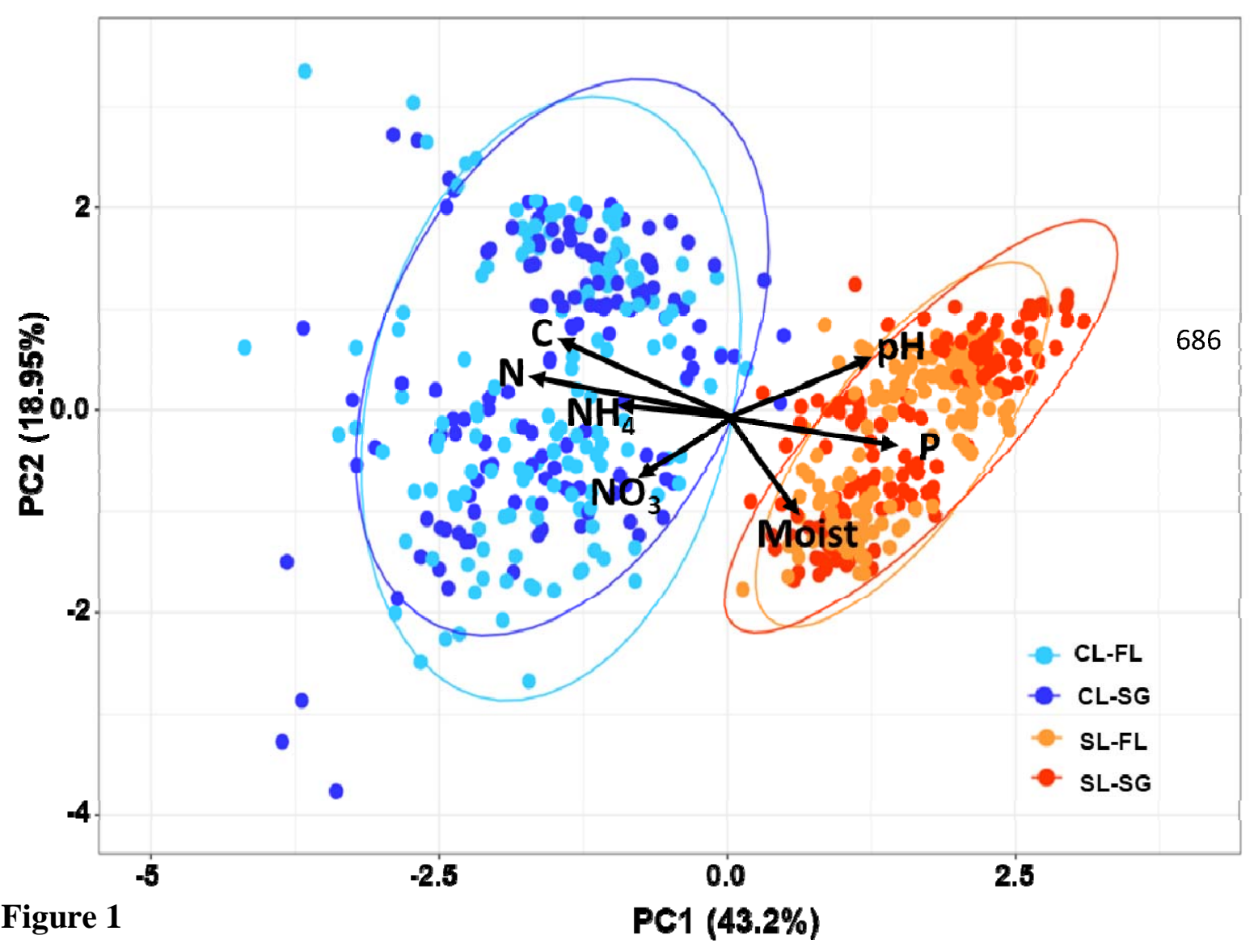


bioRxiv preprint doi: https://doi.org/10.1101/2020.03.18.997304; this version posted March 20, 2020. The copyright holder for this preprint (which was not certified by peer review) is the author/funder. All rights reserved. No reuse allowed without permission.
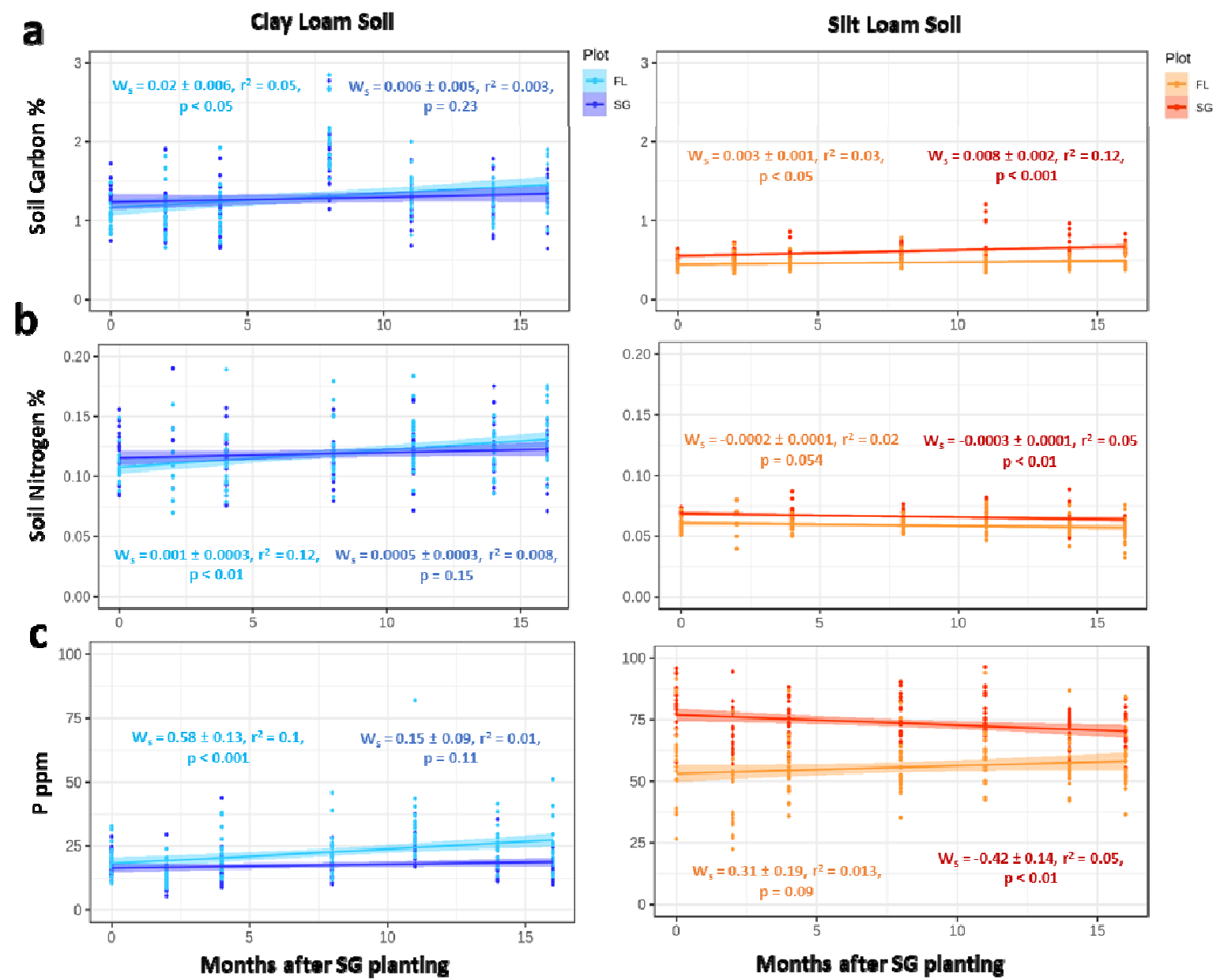

Months after SG planting 

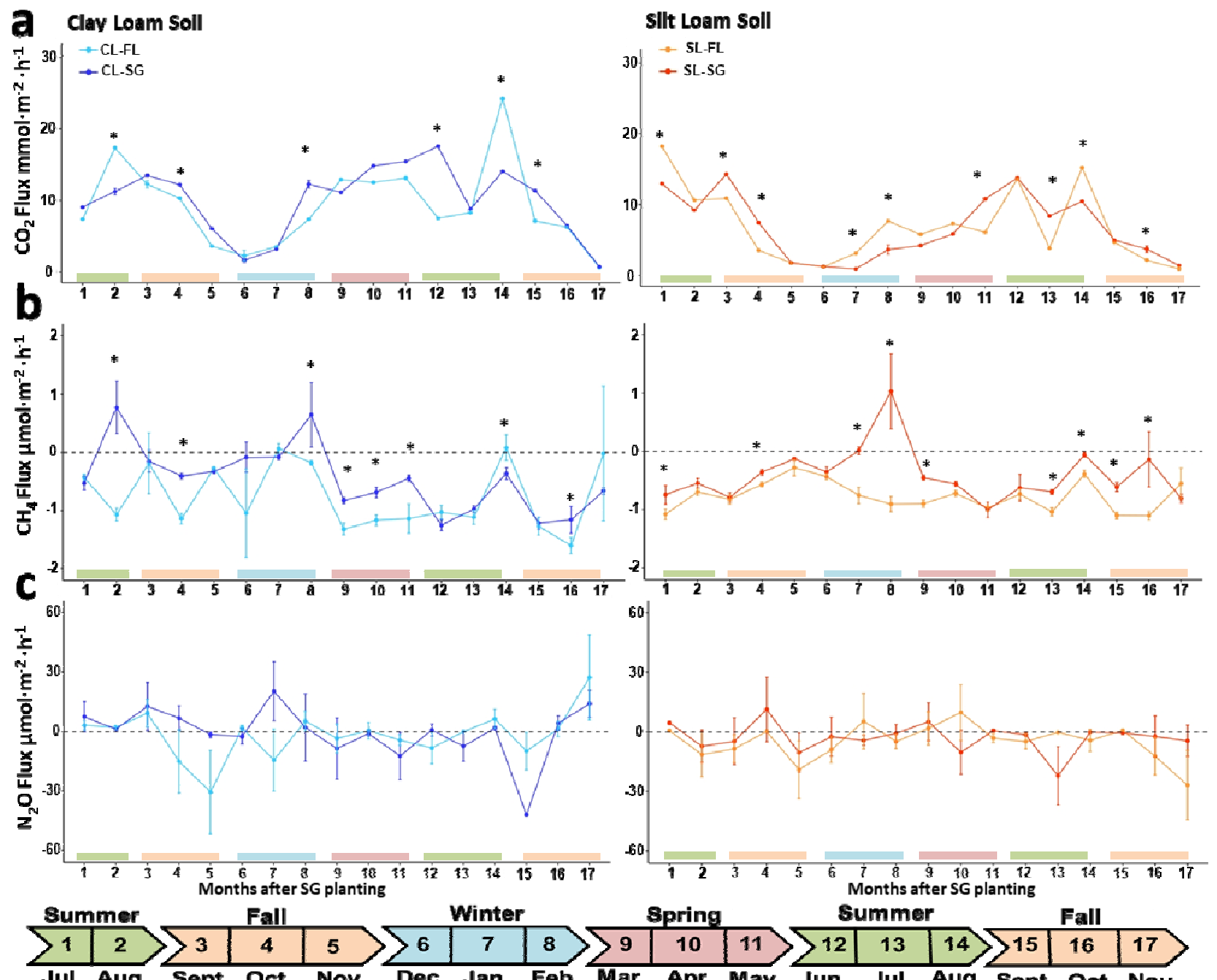

Jul. Aug. Sept. Oct. Nov. Dec. Jan. Feb. Mar. Apr. May Jun. Jul. Aug. Sept. Oct. Nov.
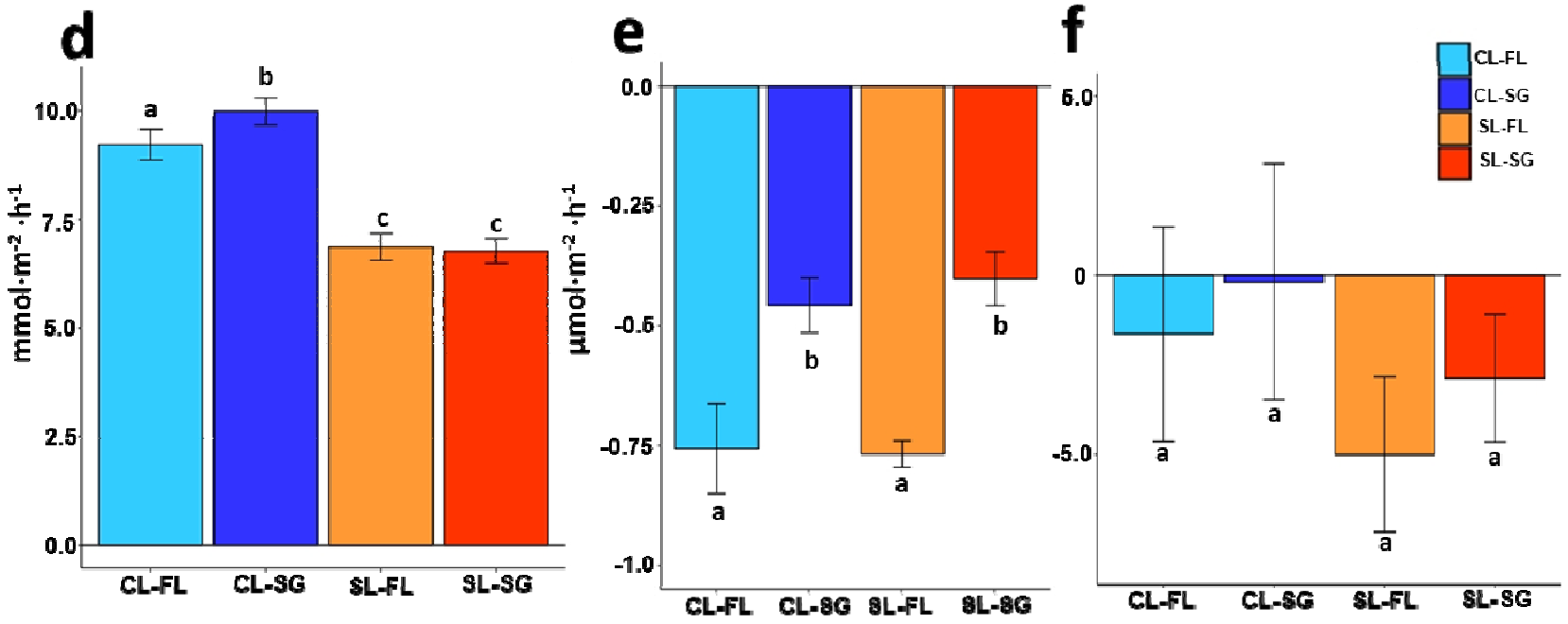

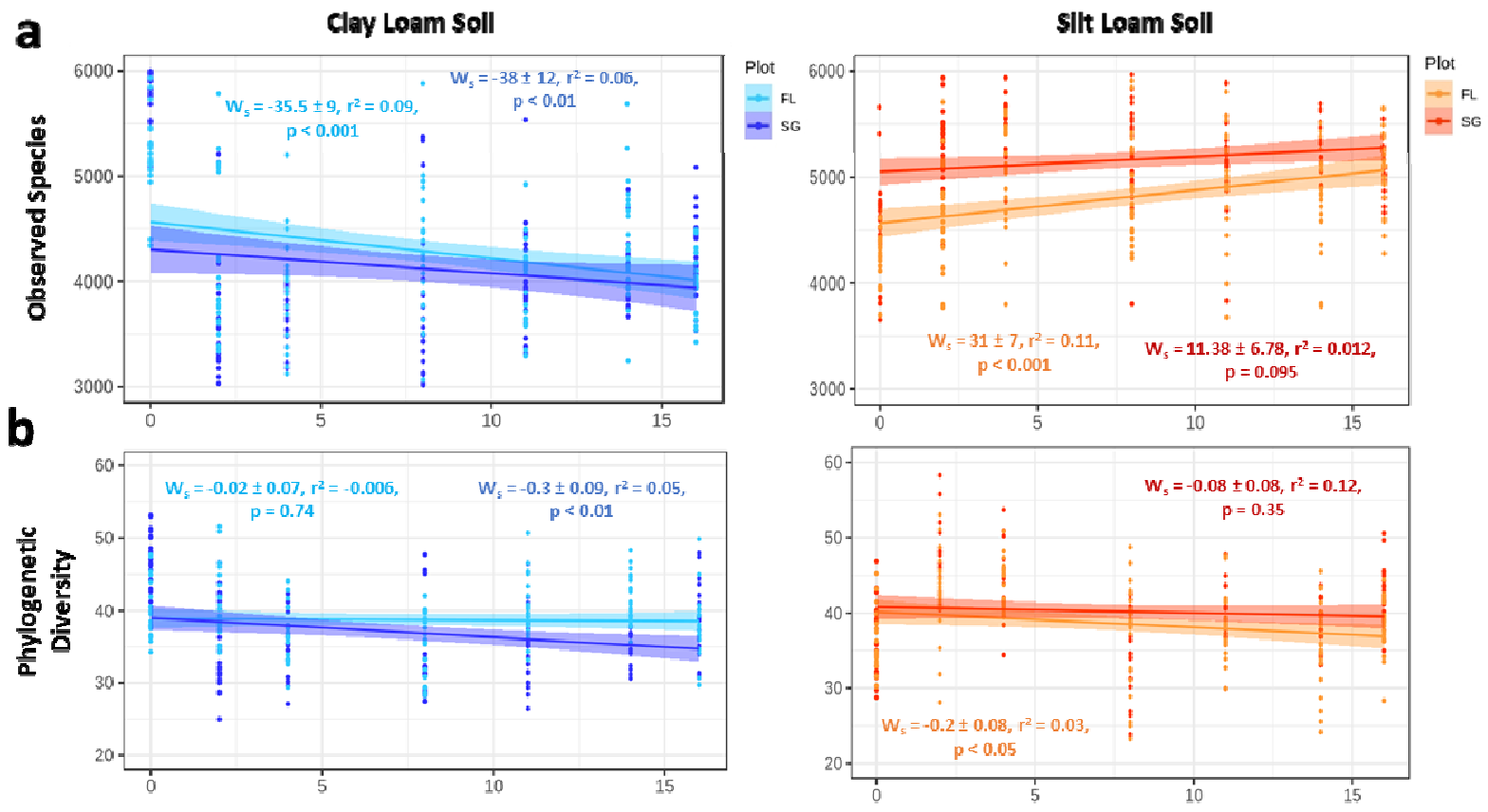

C

Months after SG planting

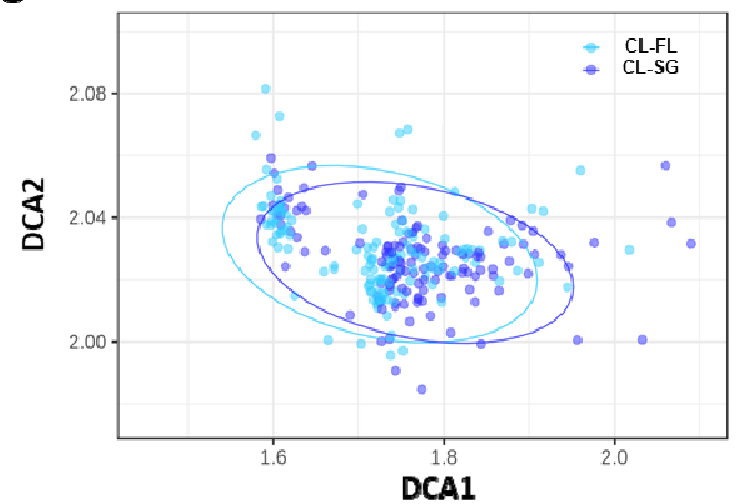

Months after SG planting

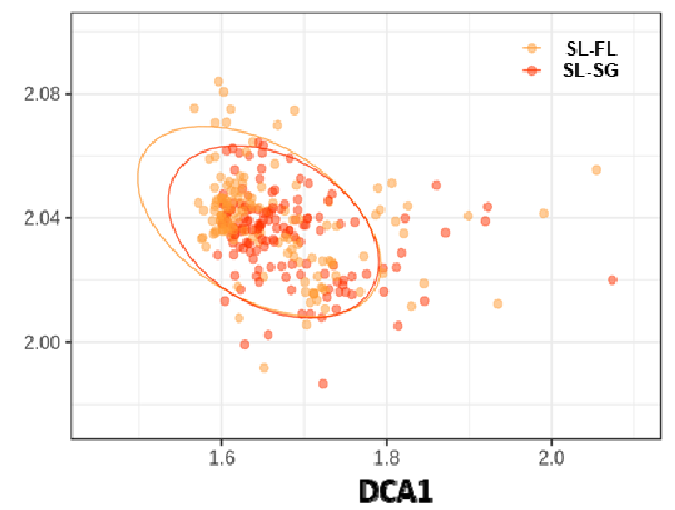




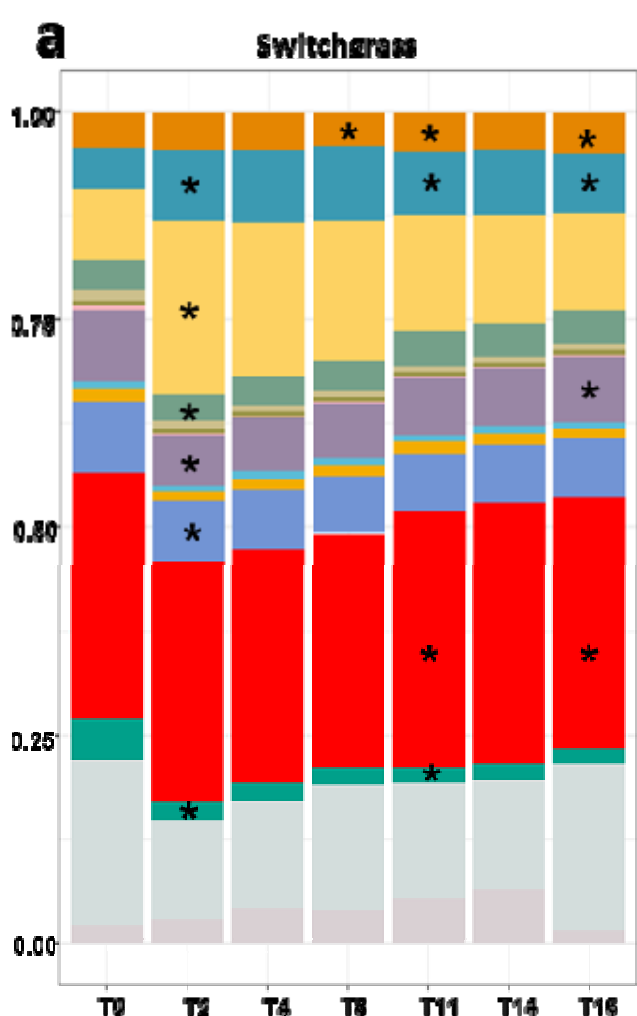

b
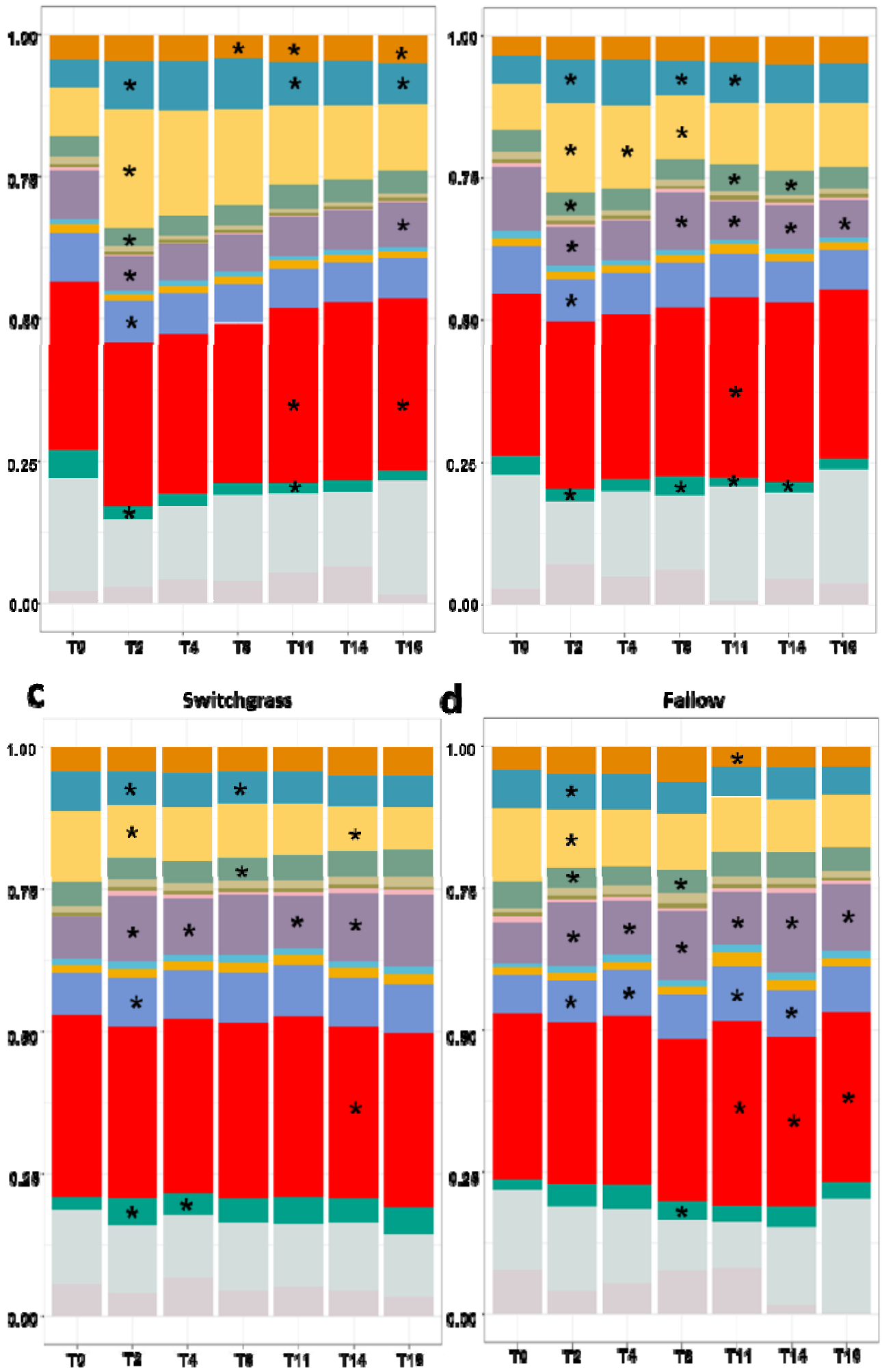
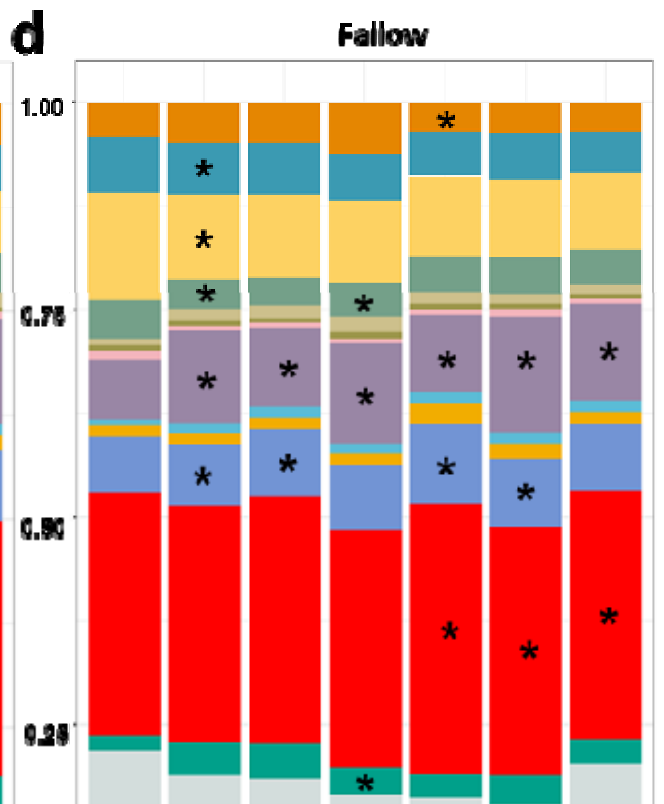

a.p
Fallow

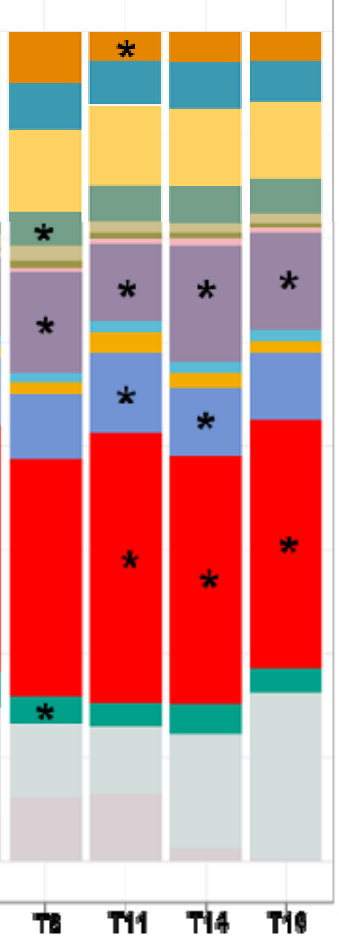

Clay Loam soll

Phylum

\begin{tabular}{|l|l}
\hline Acidobacteria \\
Actinobacteria \\
Bacteroidetes \\
Chlamydiae \\
Chloroflexi \\
Cyanobacteria/Chloroplast \\
Deinococcus-Thermus \\
Firmicutes \\
Gemmatimonadetes \\
Parcubacteria \\
Planctomycetes \\
\hline Proteobacteria \\
Verrucomicrobia \\
Unclassified \\
Others
\end{tabular}

SIlt Loam Soll 


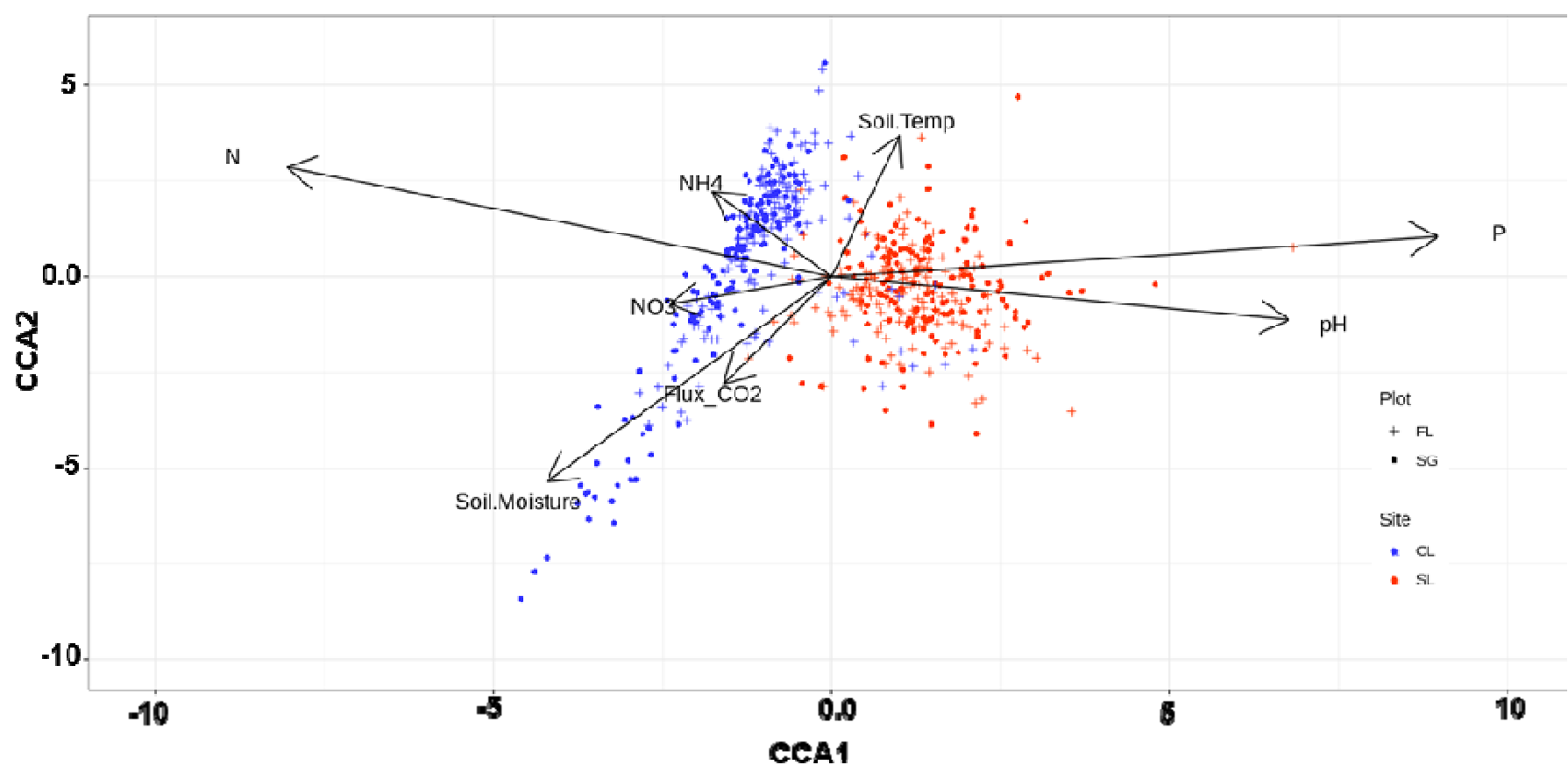

701

702

Figure 6

703

704

705

706

707

708

709

710

711

712

713

714

715

716

717

718 
2

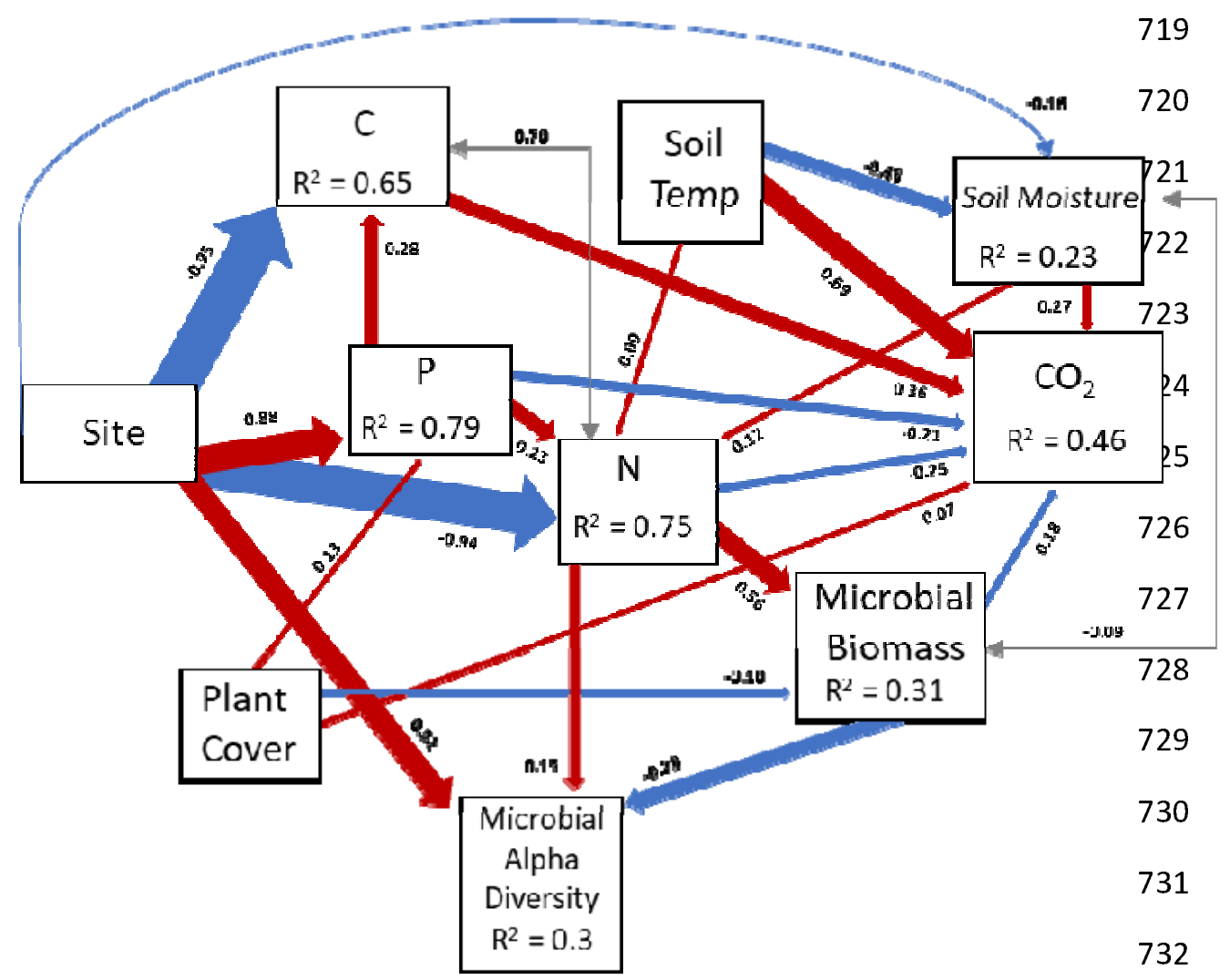

b

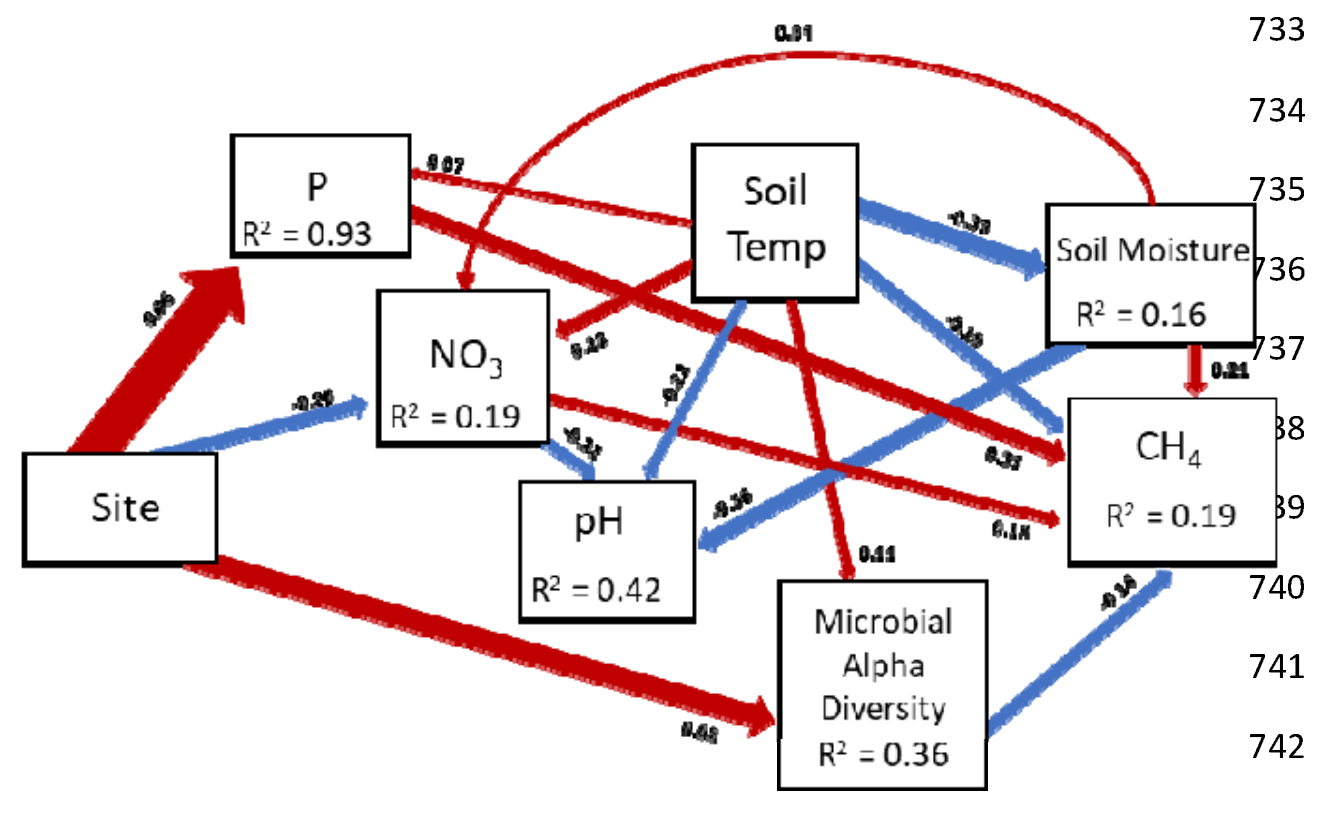



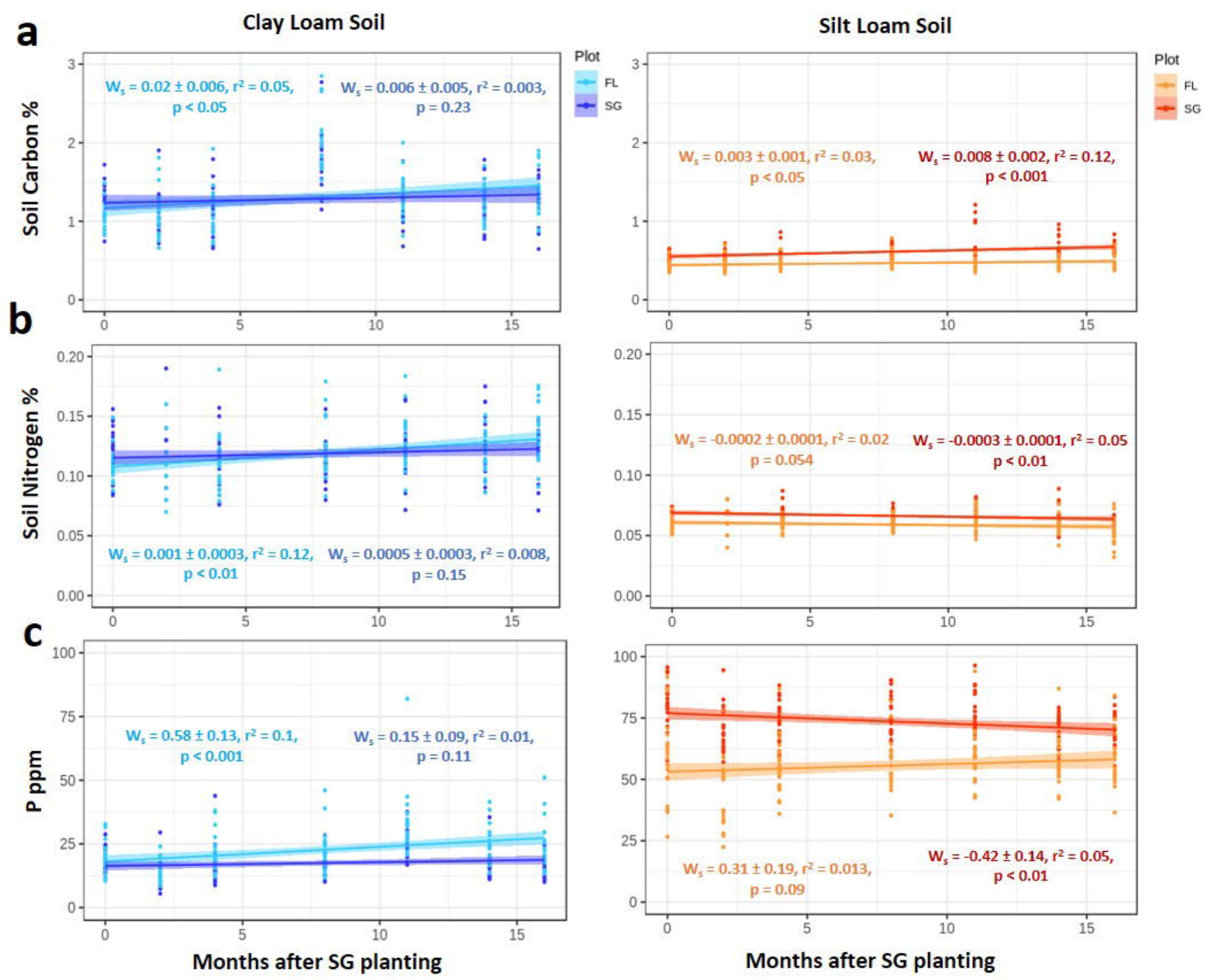

Figure 2. Changes in soil chemistry through two seasons of switchgrass establishment. a, Total soil carbon percentages; b, Total soil nitrogen percentages; c, Concentration of plant available phosphate content in parts per million. The best linear model describing the relationship is presented. $\mathrm{W}_{\mathrm{s}}$ : estimated model slope and associated error. p-values represent the significance of each model. Each time point is comprised of twenty-one replicates per plot. 
bioRxiv preprint doi: https://doi.org/10.1101/2020.03.18.997304; this version posted March 20, 2020. The copyright holder for this preprint a Clay Loam Solwhich was not certified by peer review) is the author/funderltAlbrathtsci\$erved. No reuse allowed without permission.
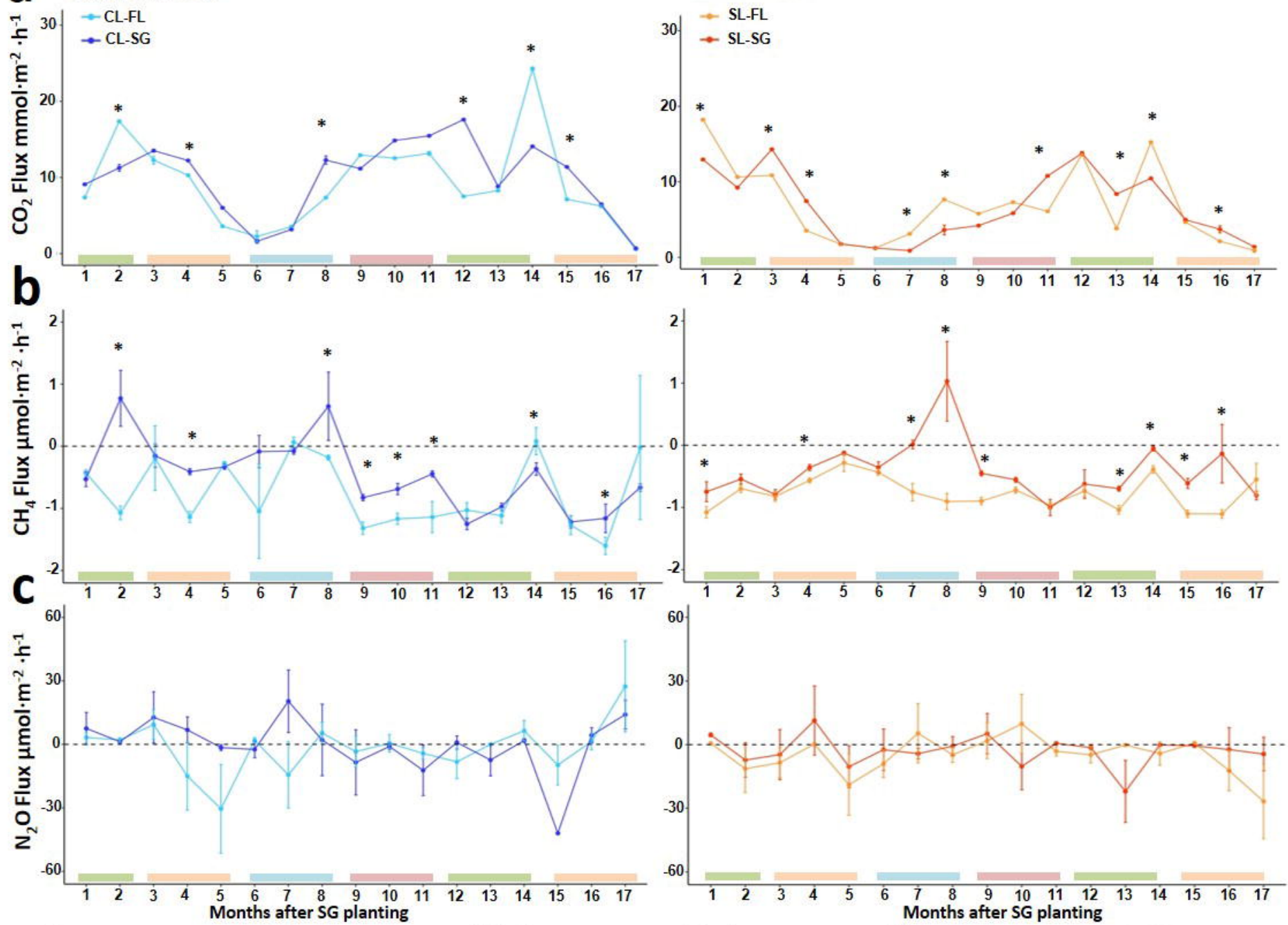

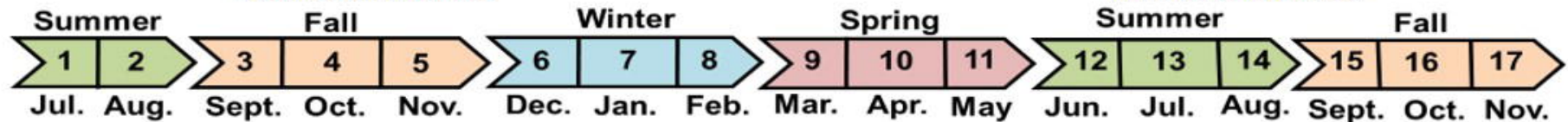
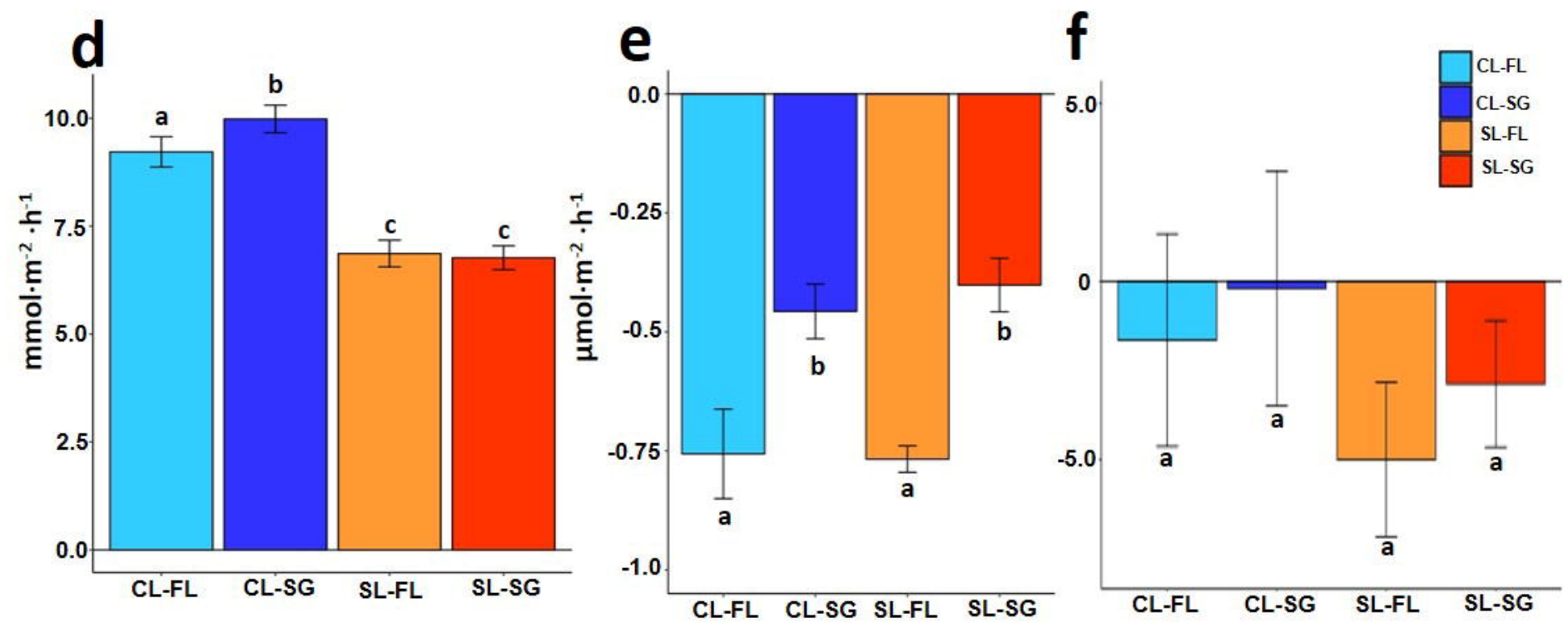

Figure 3. Greenhouse gas (GHG) fluxes during grassland conversion to switchgrass.

a, b, c: GHG fluxes at each site over 17 months (mean and standard error estimated using 21 replicates for each time points) for: a, carbon dioxide flux; $\mathbf{b}$, methane flux; $\mathbf{c}$, nitrous oxide. d, Average GHG fluxes over 17-months for: d, carbon dioxide; e, methane flux; f, nitrous oxide flux. Different letters and asterisk indicate significant difference between groups by Wilcox sign test with p-value $<0.01$. 

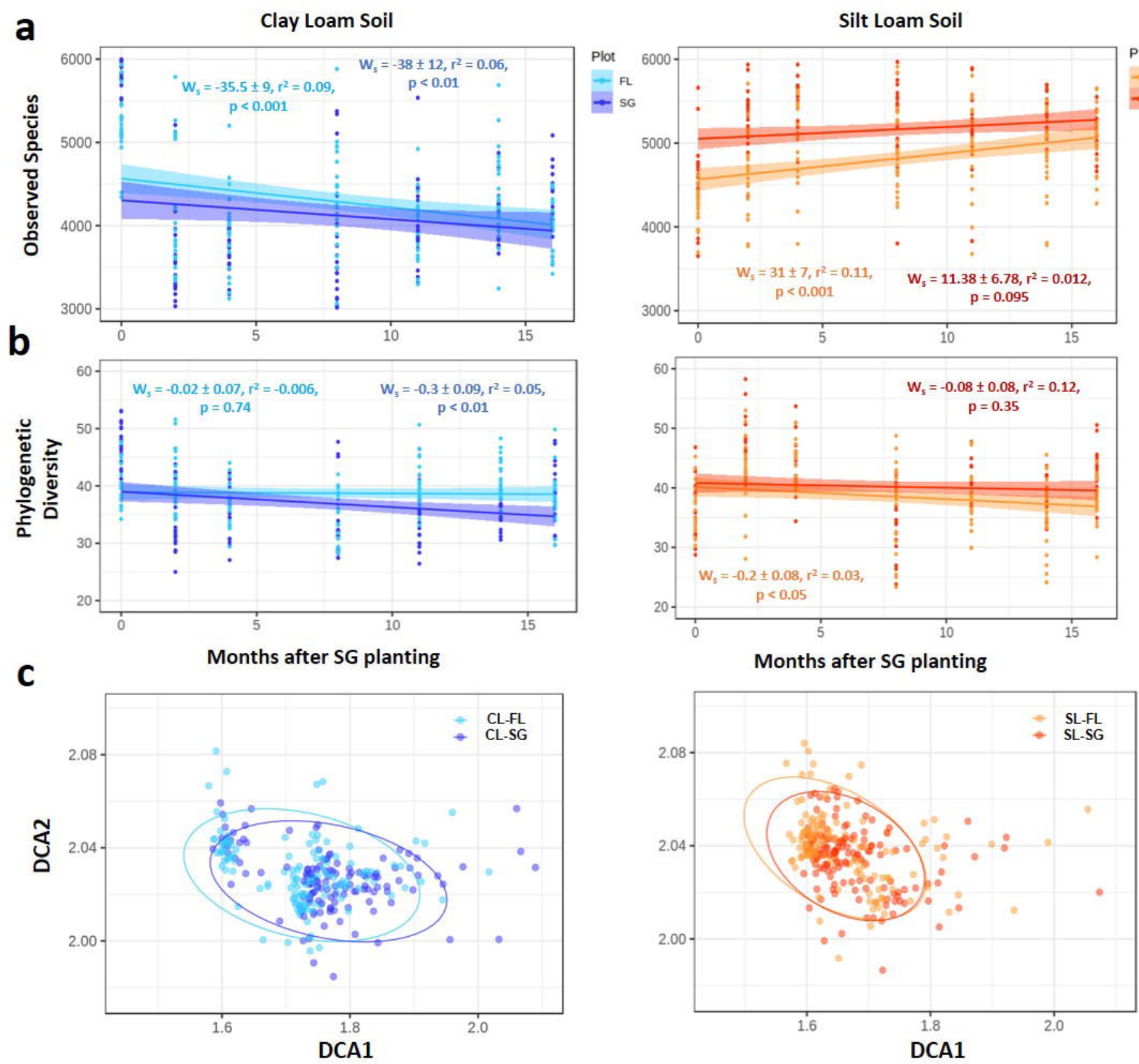

Figure 4. Changes in microbial diversity and structure in response to switchgrass planting. a, Number of observed species through time; b, Phylogenetic diversity. c, Detrended correspondence analysis of the $16 \mathrm{~S}$ community separated by site for all time points and plots. Significant differences were found between sites, plant cover types, and through time (PERMANOVA, $\mathrm{p}<0.01$ ). Dark colors represent the switchgrass samples. 


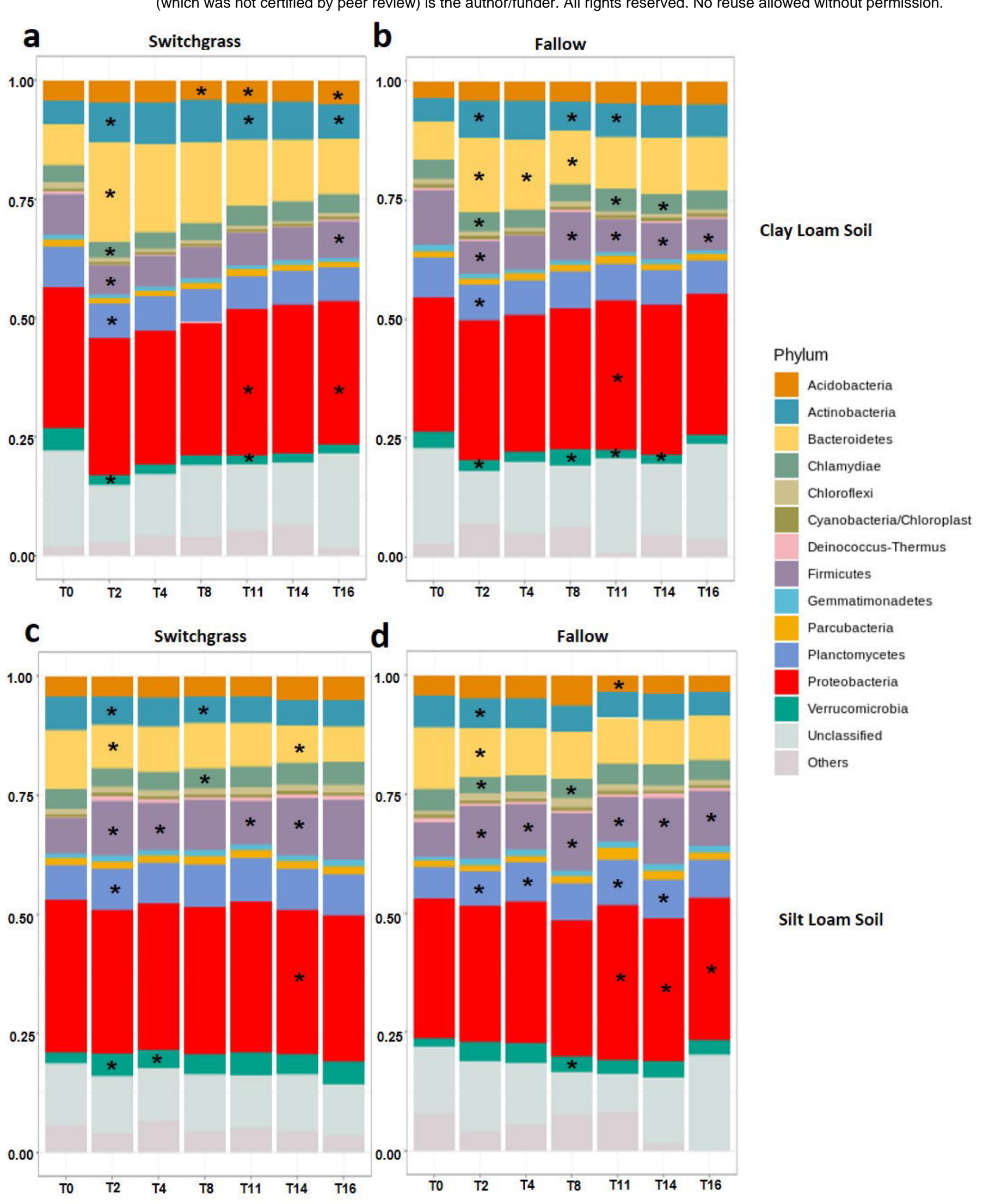

Figure 5. Changes of relative abundance for major phyla. Taxonomic identity was determined with the RDP classifier at $80 \%$ sequence match criteria. OTU table was trimmed by abundant OTUs $(>0.001 \%)$. Difference between time points within each plot for: a, Clay-loam switchgrass (CL-SG) plot; $\mathbf{b}$, Clay-loam fallow (CL-FL) plot; Silt-loam switchgrass (SL-SG) plot; Silt-loam fallow (SL-FL) plot. Significant differences between the pervious time point for each group denoted by asterisk $(*)$ symbols within each phyla bar. 


\section{a}

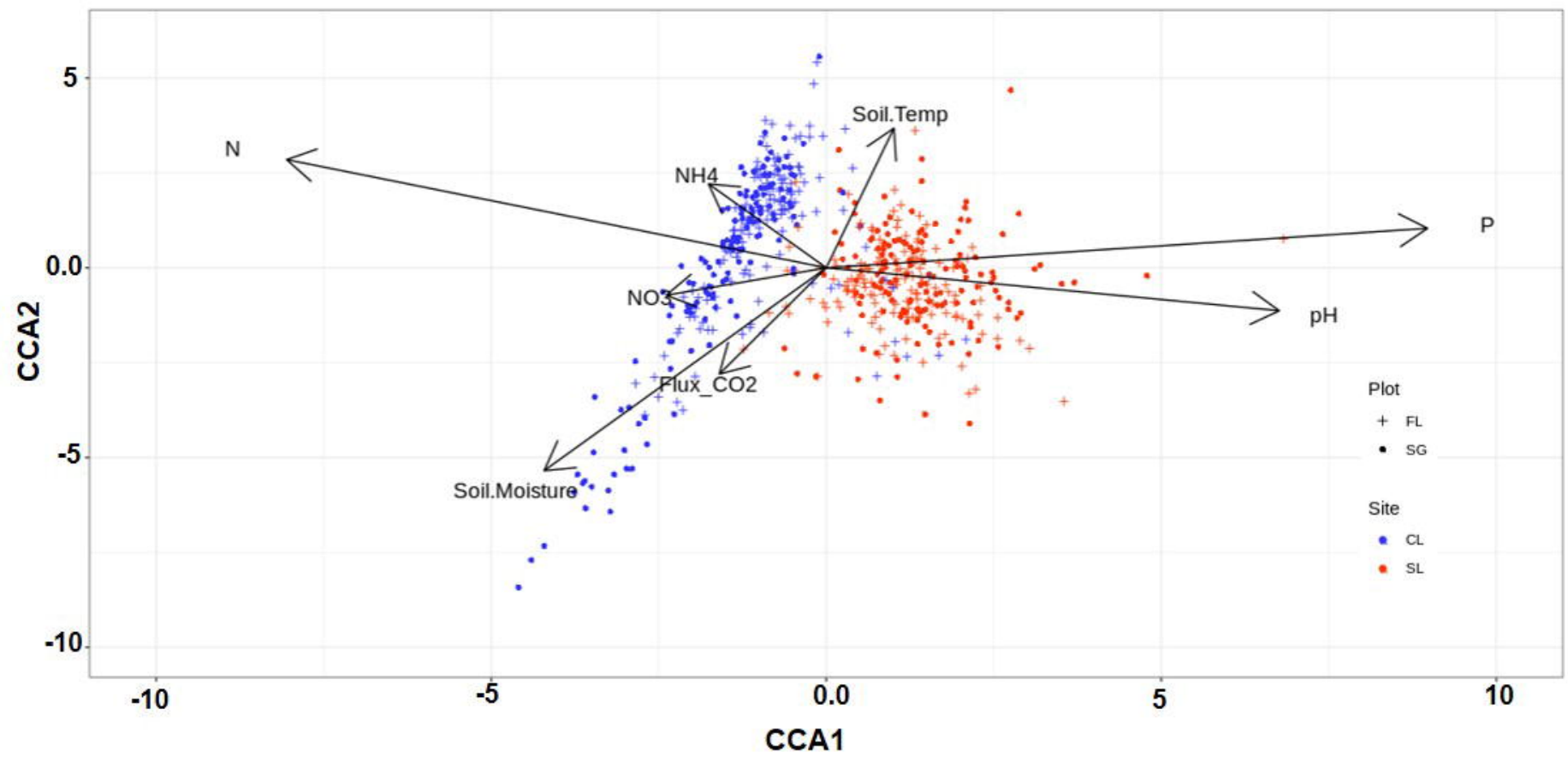

Figure 6. Relationships between environmental factors and microbial communities structure. Canonical correspondence analysis (CCA) linking microbial communities structure with environmental variables. Samples are shown by plot and site type with significant environmental variables shown in black arrows. 


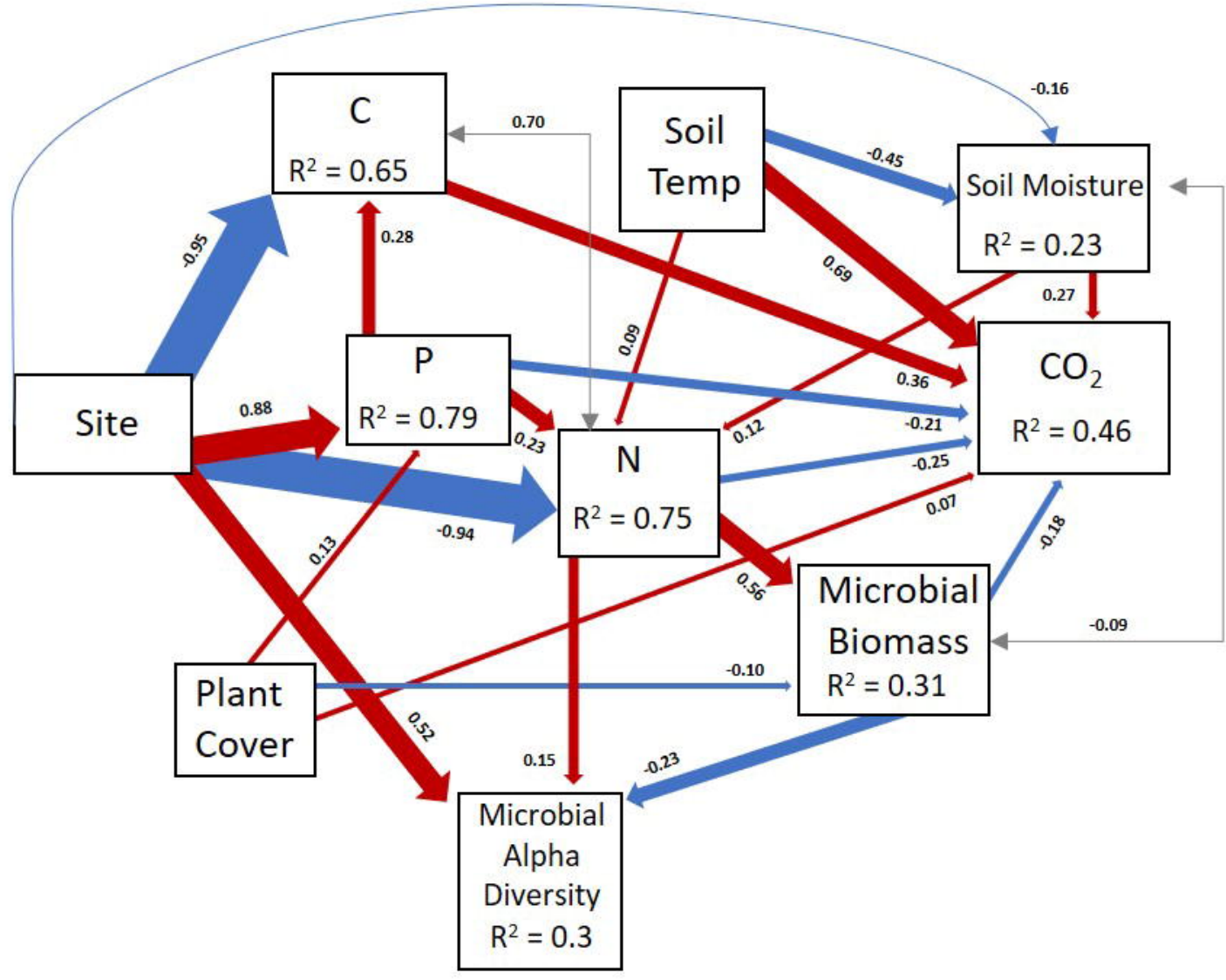

b

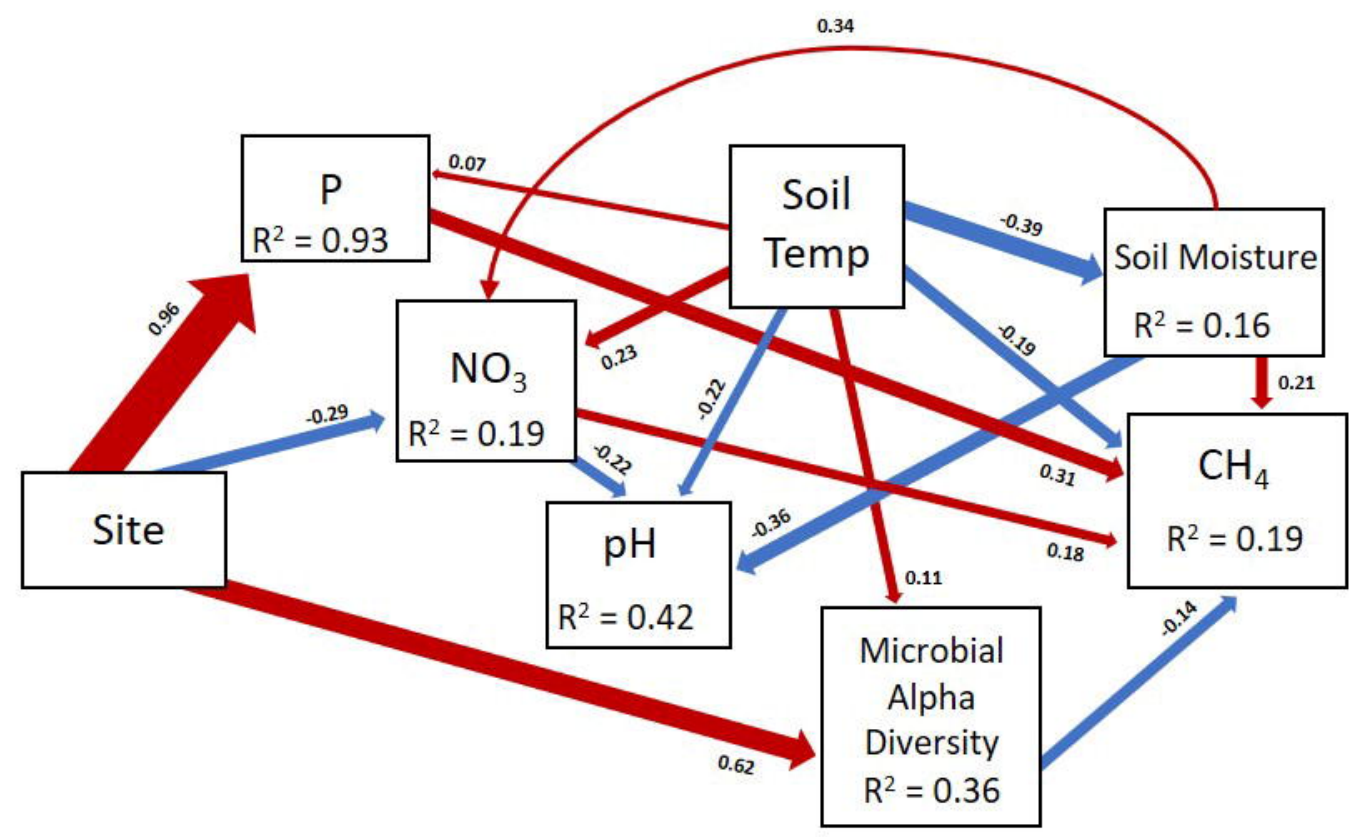

Figure 7. Structural equation modeling showing the relationships among environmental variables and GHG fluxes. a: Model for total carbon dioxide flux generated from the seasonal data $\left(\chi^{2}=25.806\right.$, d.f. $=18, P=0.104, n=588)$. $\mathbf{b}$ : Model for methane flux generated from seasonal data of switchgrass plots only $\left(\chi^{2}=10.116\right.$, d.f. $\left.=9, P=0.341, n=294\right)$. Red and blue arrows represent significant $(\mathrm{p}<$ $0.05)$ positive and negative pathways, respectively. Numbers near the pathway arrows indicate the standard path coefficients $(\beta)$. Width of the arrows are proportional to the strength of the relationship. Gray arrows represent residual correlations accounted for in the model. Plant Cover $=$ Switchgrass (positive) or mixed annual grassland plant cover (negative) at the plot; Site $=\mathrm{SL}$ (positive) or CL (negative) soil site; $\mathrm{CO}_{2}=$ total soil carbon dioxide flux; Soil Temp = soil temperature at a depth of 10 $\mathrm{cm}$ for bare soil in degrees Celsius; Soil Moisture $=$ gravimetric per cent soil moisture; $\mathrm{P}=$ plant available phosphorus content; Microbial Alpha Diversity = number of observed bacterial species per sample; $\mathrm{NO}_{3}=$ nitrate concentrations; $\mathrm{CH}_{4}=$ methane flux; and $\mathrm{pH}=$ soil $\mathrm{pH}$. 

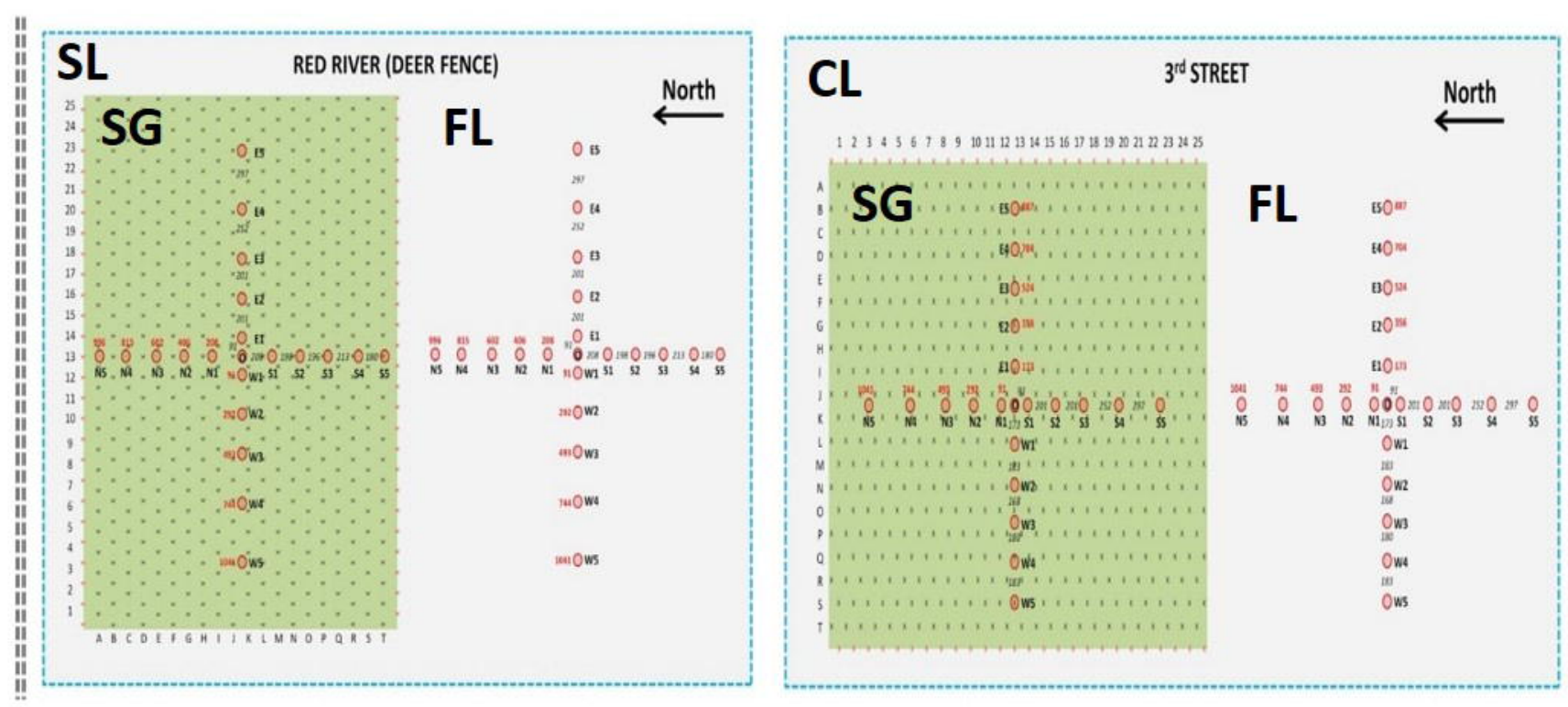

\section{C}

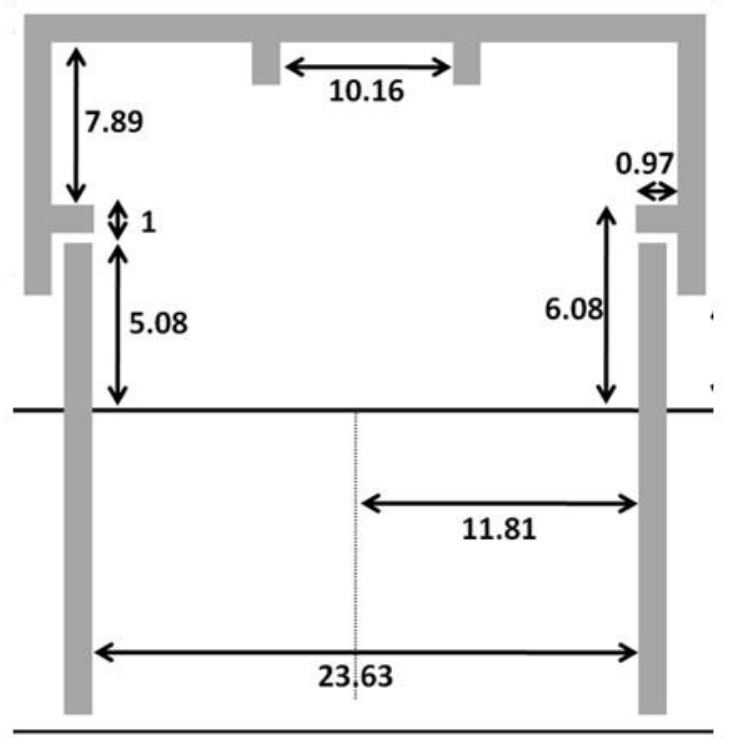

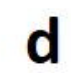

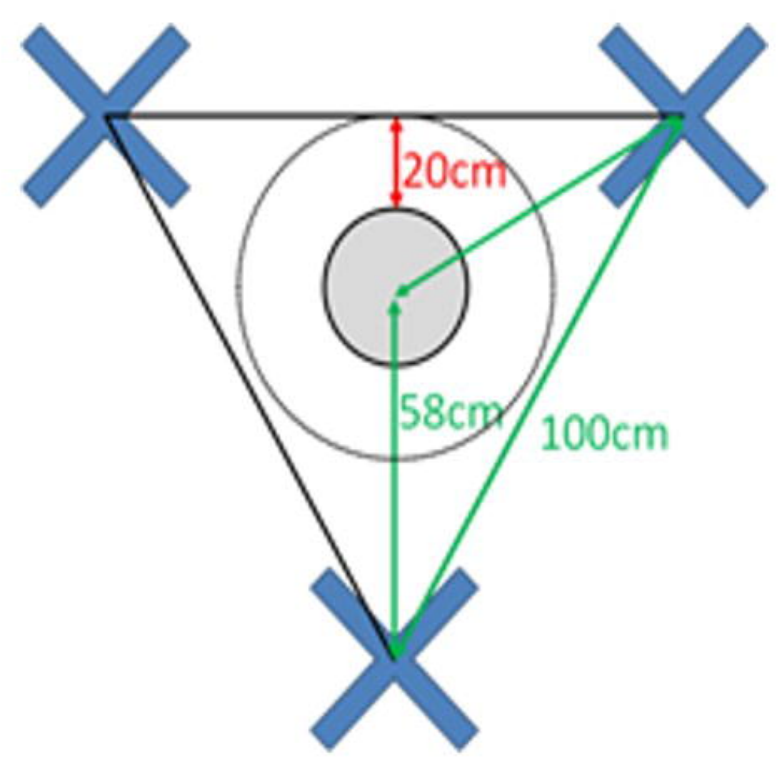

Fig. S1, Layout for the field sites, collar positions, and soil sampling details: a, layout of the SL field site and location of trace gas collars for each plot; $\mathbf{b}$, layout of the CL field site and location of the trace gas collars for each plot; $\mathbf{c}$, diagram of trace gas collar and chamber dimensions; d, diagram of collar position in relation to switchgrass plants and soil sampling details. Blue X's represent switchgrass plants and the gray circle represents the trace gas collar. 


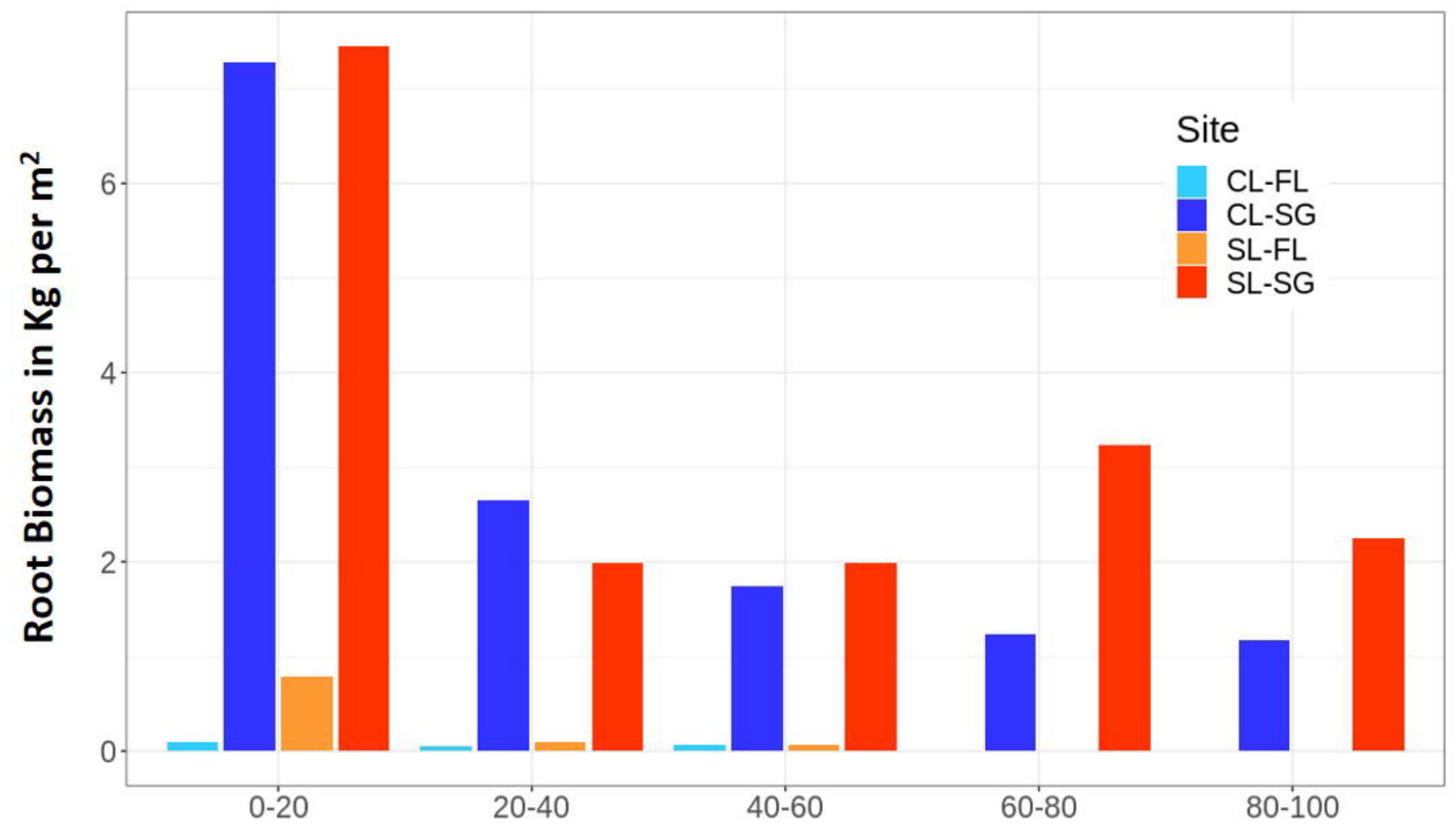

Soil Depth in cm

b

C

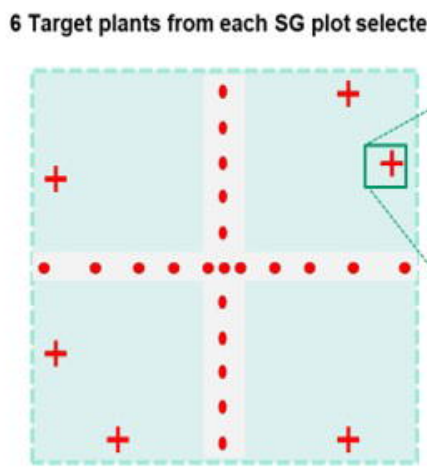

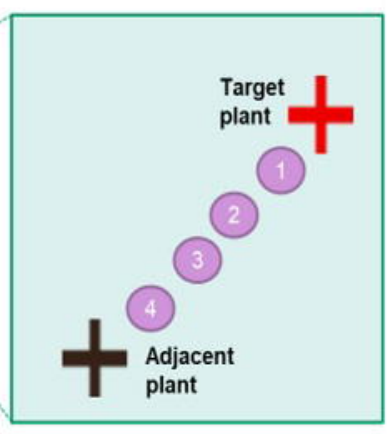

4 Soil Cores with 5 Depths between 2 plants:

$0-20,20-40,40-60,60-80,80-100 \mathrm{~cm}$

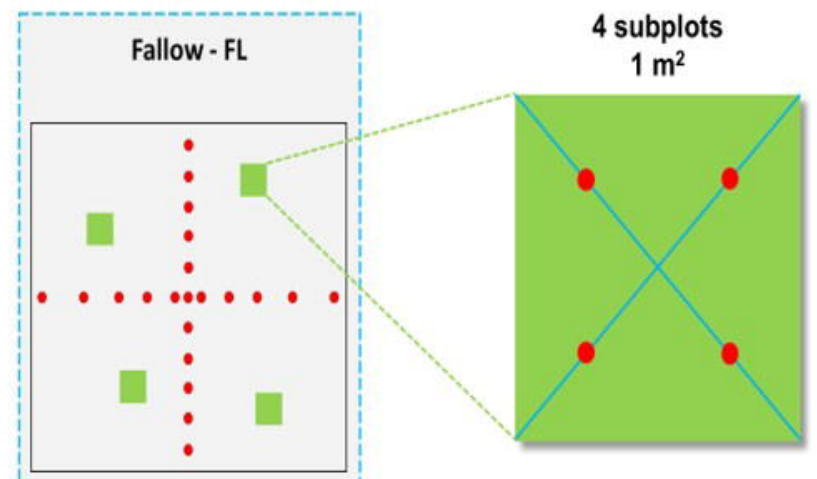

Fig. S2, Root biomass estimates and methods for: a, difference between fallow and switchgrass plots for estimated root biomass by depths; b, graphic for how switchgrass plants were selected for root biomass estimation; c, graphic for how fallow root biomass estimation was conducted using four $1 \mathrm{~m}^{2}$ subplots in each quadrant of the plot. 

(which was not certified by peer review) is the author/funder. All rights reserved. No reuse allowed without permission.

a

b
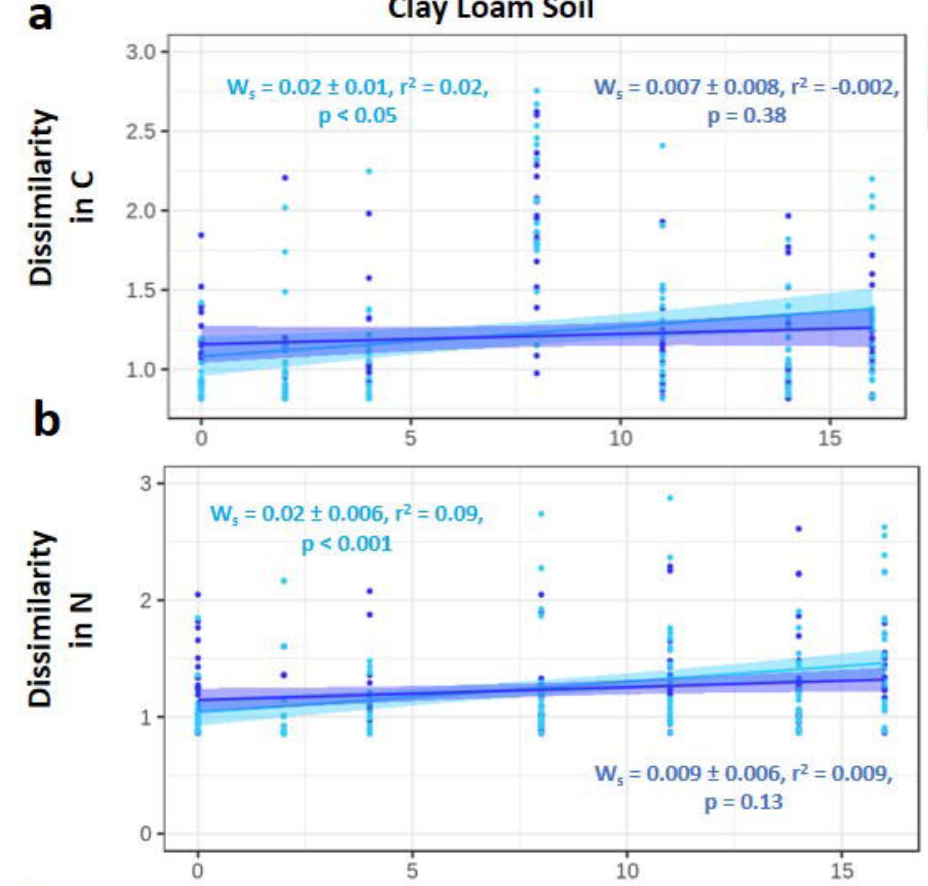

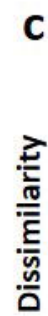

d
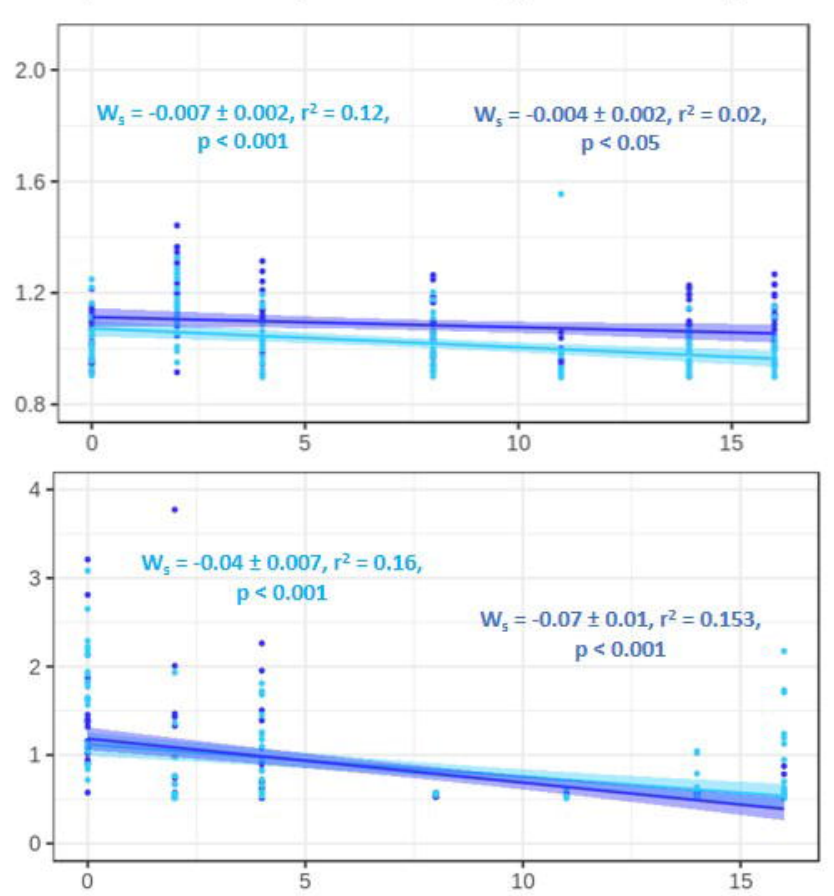

e

e

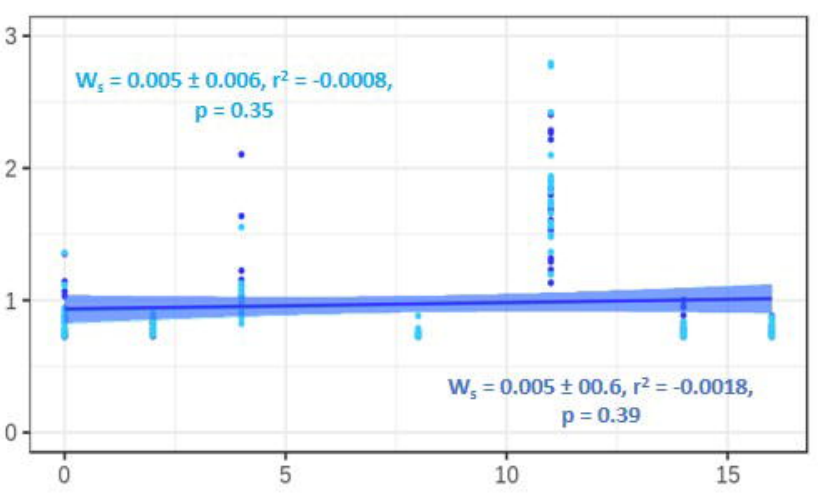

Months after SG planting
Silt Loam Soil
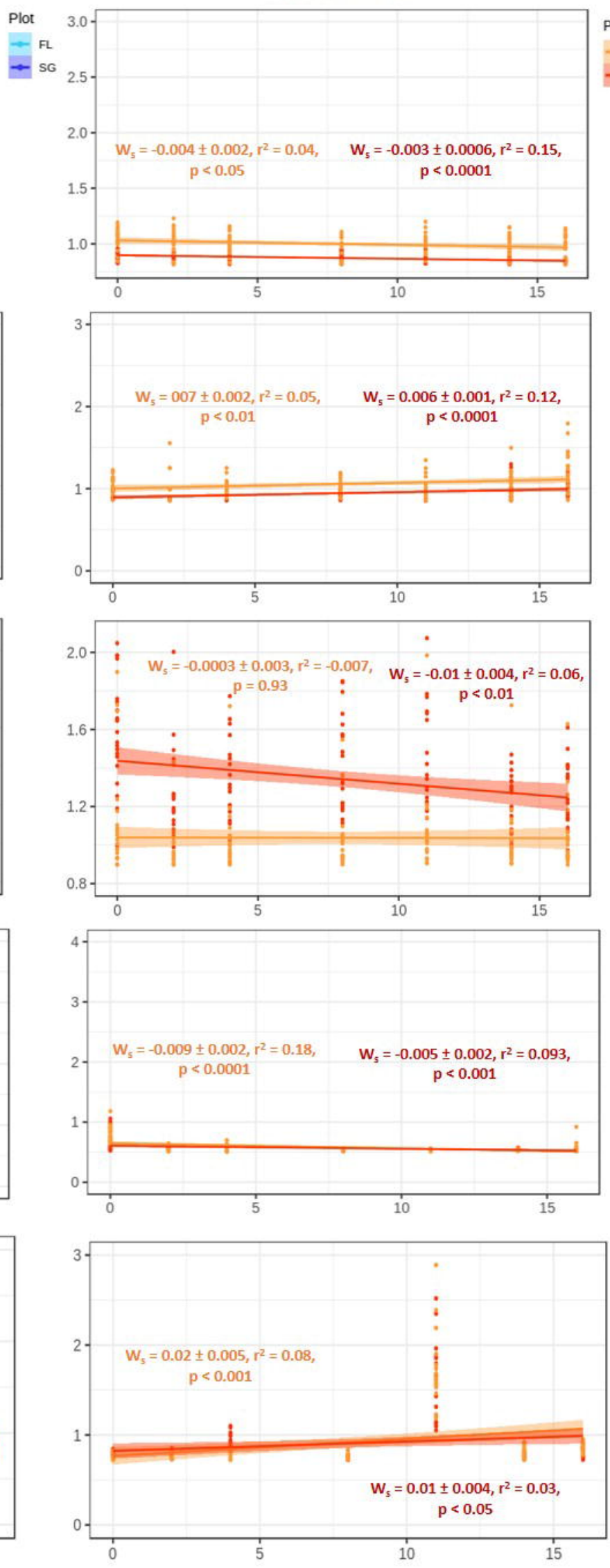

Months after SG planting

Fig. S3, Dissimilarity between soil chemistry samples through the seasons at each site between SG and FL plots for: a, dissimilarity in soil carbon samples; b, dissimilarity in soil nitrogen content; c, dissimilarity in plant available phosphate content; $\mathbf{d}$, dissimilarity in nitrate content; e, dissimilarity in ammonium. Ws is the slope of each line and the error associated with each slope while p-values represent the significance of each trend line. Each time point is comprised of twenty-one replicates per plot. 

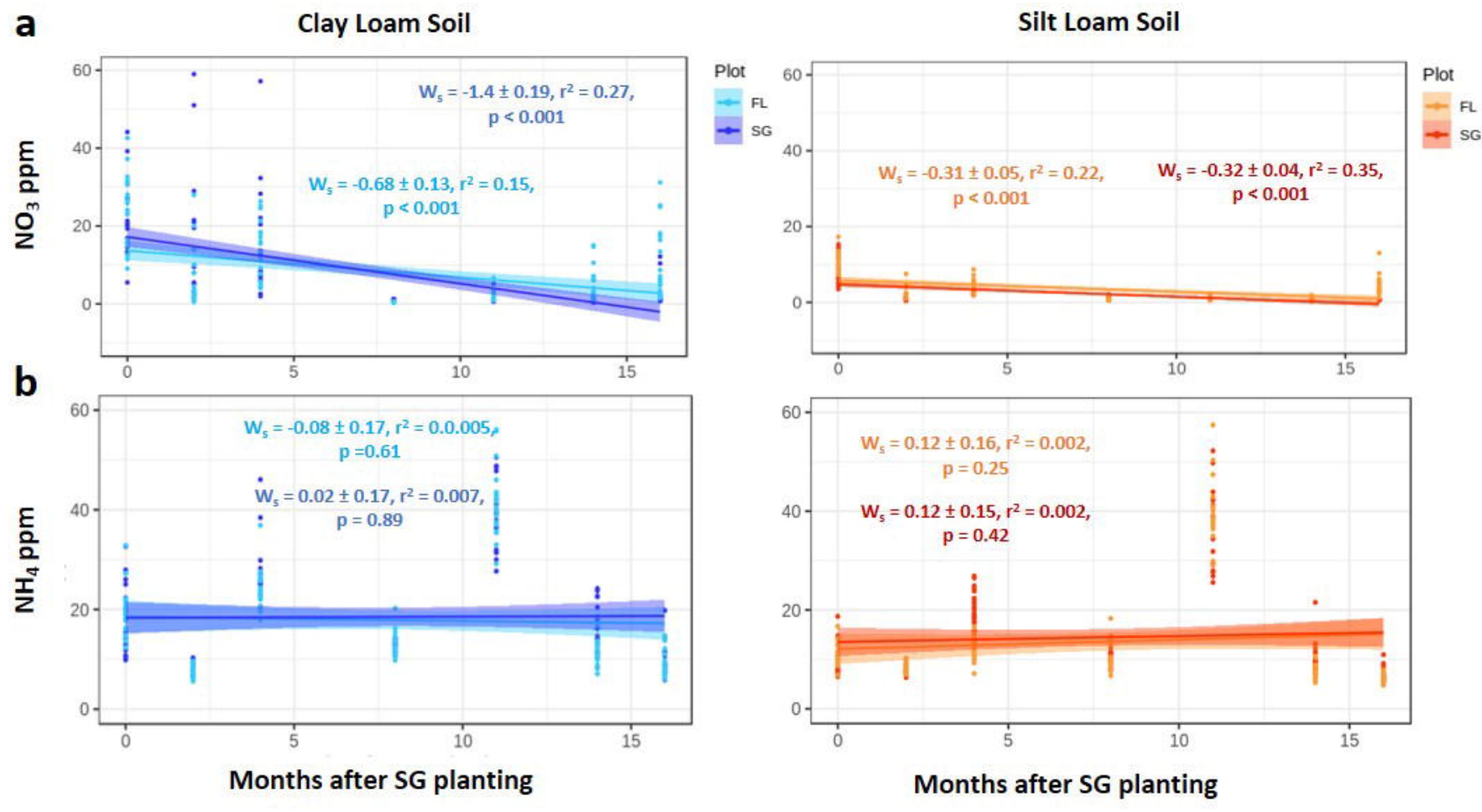

Fig. S4, Changes in soil chemistry through the seasons at each site between SG and FL plots for: a, concentration of nitrate content; $\mathbf{b}$, ammonium content. Ws is the slope of each line and the error associated with each slope while p-values represent the significance of each trend line. Each time point is comprised of twenty-one replicates per plot. 

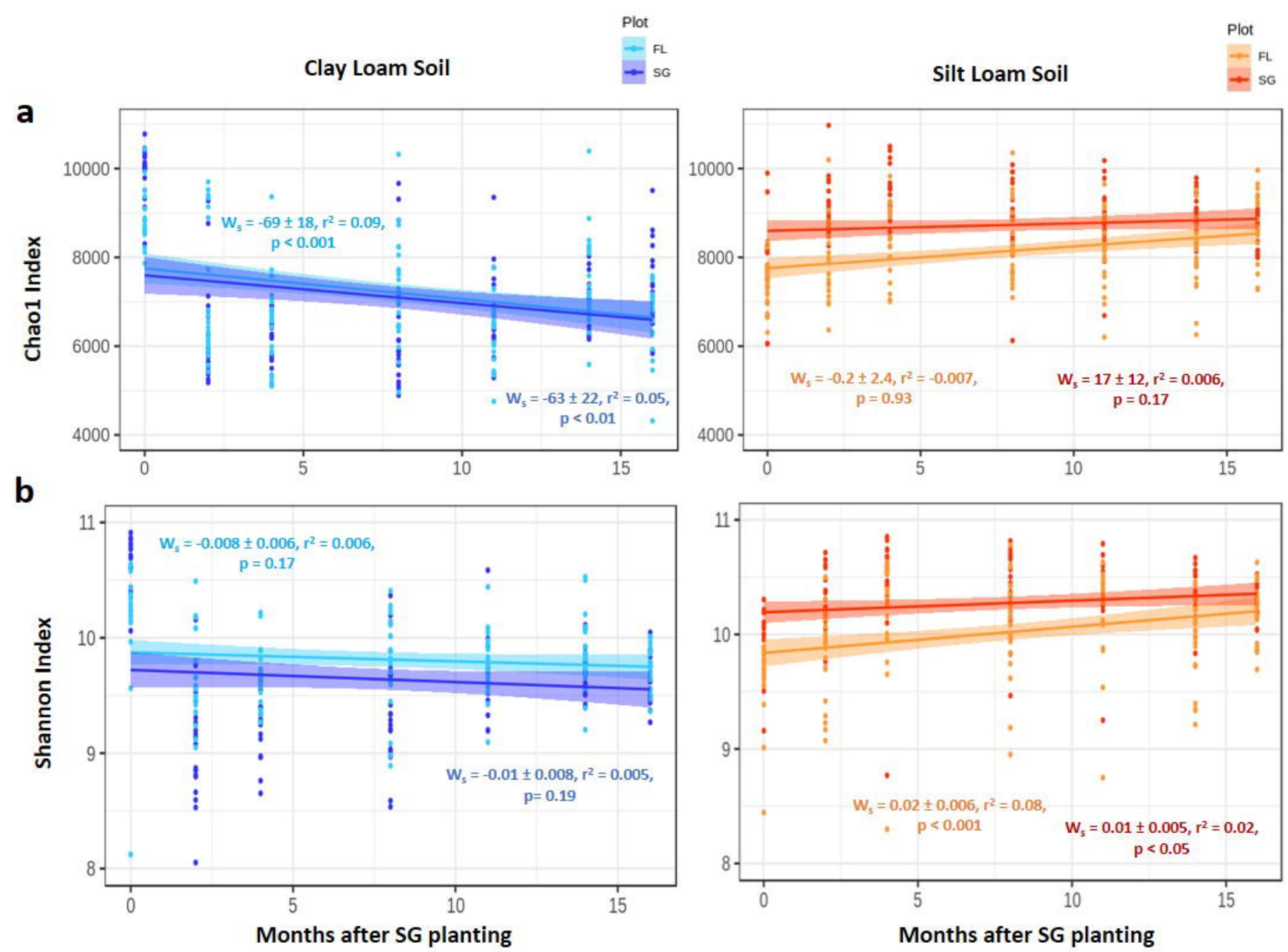

Fig. S5, Change in microbial alpha diversity measures through the seasons at each site between SG and FL plots for: $\mathbf{a}$, chao1 index; $\mathbf{b}$, Shannon index. Ws is the slope of each line and the error associated with each slope while $p$-values represent the significance of each trend line. Each time point is comprised of twenty-one replicates per plot. 


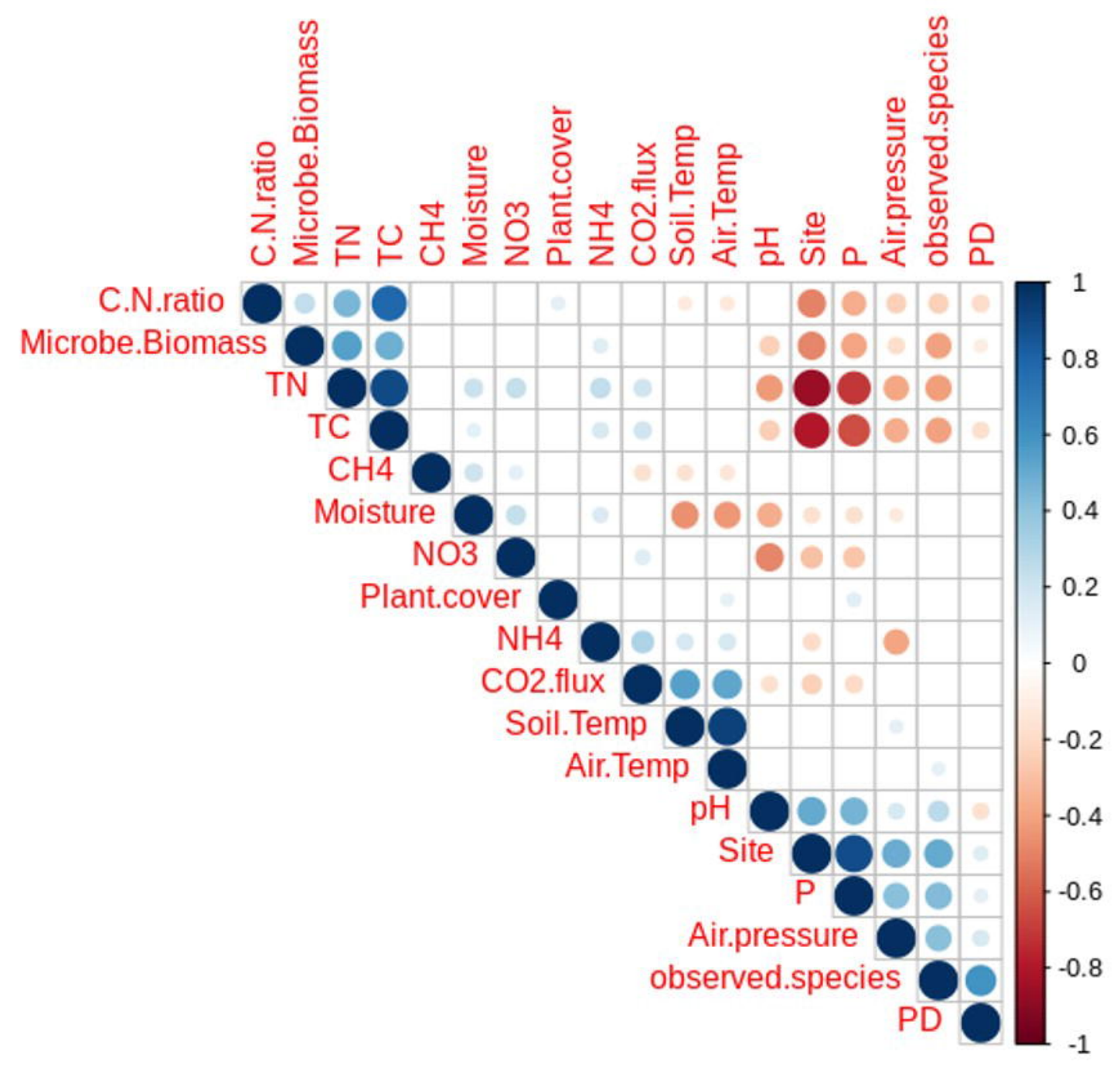

Fig. S6, Correlation plot between environmental, microbial, and soil geochemistry variables. Blue circles indicate significant positive correlations while red circles indicate negative correlations. Larger darker circles indicate a more significant and stronger correlation between variables. Positive correlations for site represent SL site while negative correspond to the CL site. 'Microbe.Biomass' was estimated using DNA concentrations after soil extractions. 'observed.species' is the total species richness (alpha diversity) of the samples. 'PD' represents the whole tree phylogenetic diversity of the plots. Positive correlations for 'Plant.cover' represent switchgrass plots and negative for fallow plots. 